\title{
A Zn(II)-Organic Framework as a Fluorescent Probe for the Aqueous Phase Detection of Nitroaromatic Explosive and $\mathrm{Cr}(\mathrm{III})$ ion
}

\section{Samrah Kamal}

Aligarh Muslim University

Mohd Khalid ( $\sim$ khalid215@gmail.com )

Aligarh Muslim University

M. Shahnawaz Khan

Aligarh Muslim University

M. Shahid

Aligarh Muslim University

Musheer Ahmad

Aligarh Muslim University

\section{Research Article}

Keywords: Metal-organic framework, TNP detection, Fluorescence quenching, Cr3+ sensing

Posted Date: September 29th, 2021

DOI: https://doi.org/10.21203/rs.3.rs-934804/v1

License: (a) This work is licensed under a Creative Commons Attribution 4.0 International License. Read Full License 


\section{Abstract}

From the perspective of environment, civilian safety and human health it is utmost important to selectively and sensitively detect hazardous substances in the running water. In the last few decades, metal organic frameworks (MOFs) have been utilized for the detection of lethal substances in the aqueous phase using fluorescence method. Herein, a highly fluorescent MOF, Zn-MOF-1, namely, $\left\{\left[\mathrm{Zn}_{2}(\text { pydc })_{2}(\mathrm{DMF})\right] \cdot 2 \mathrm{DMF}\right\}_{n}$, based on the ligand pyridine-2,5-dicarboxylic acid $\left(\mathrm{H}_{2}\right.$ pydc), was synthesized by employing solvothermal conditions. The Zn-MOF-1 was thoroughly characterized by crystallographic, PXRD, elemental, FTIR, and TG analysis. Single crystal data elucidated the exact structure of Zn-MOF1. Due to its better emission spectra, the fluorescence sensing behavior of Zn-MOF-1 was checked in the aqueous medium. It was found that $\mathrm{Zn}$-MOF-1 could detect $\mathrm{Cr}^{3+}$ with high sensitivity and selectivity and serve as an excellent fluorescent probe for TNP among other interfering nitroaromatic compounds in aqueous media. Furthermore, a plausible sensing mechanism has been demonstrated employing UVVisible, fluorescence, and theoretical data. The observed $\mathrm{K}_{\mathrm{sv}}$ values for TNP and $\mathrm{Cr}^{3+}$ are $2.1 \times 10^{8} \mathrm{M}^{-1}$ and $1.46 \times 10^{7} \mathrm{M}^{-1}$, respectively. Selective fluorescence quenching with high $\mathrm{K}_{\mathrm{sv}}$ values and low detection limits validates the superior sensing performance shown by Zn-MOF-1 toward TNP and $\mathrm{Cr}^{3+}$. Thus, the finetuning of MOF for the detection of hazardous substances in wastewater is a challenging task and needs to address in future endeavors.

\section{Introduction}

From the point of constantly increasing pollution problems worldwide, novel functional materials have attracted considerable attention towards chemist due to its fast response time, high sensitivity, selectivity, and low limit of detection to sense the pollutants. Metal-organic frameworks (MOFs), a kind of evolving crystalline materials, comprises organic linkers and inorganic building blocks, and these rigid, stable, and emerging materials continue to be a subject of intense research [1]. Owing to their structural diversity, tunable pore size, and potential applications in a broad range of areas; for instance, drug delivery and release [2], heterogeneous catalysis [3], adsorption [4], gas storage, separation [5] and fluorescence sensing [6]. MOFs, as fluorescent probes, possess great superiorities including, low cost, simplicity, rapid response, high sensibility, liable recyclability, ease of handling and sample preparation [7]. On the other hand, the other detection methods such as atomic absorption spectroscopy, cyclic voltammetry, inductively coupled plasma mass spectrometry (ICPMS), gas chromatography - mass spectrometry, highpressure liquid chromatography, ion mobility spectroscopy and raman spectroscopy [8] are costly, time consuming and tough to operate [9]. The abundance of fluorescent MOF materials has been scrutinized in the literature to date for sensing purpose which involves sensing of various hazardous substances such as cations-anions, volatile organic compounds, small molecules, Nitroaromatic compounds (NACs) [10]. NACs are among the most common malignant organic pollutants due to their toxic nature, highly explosive, and difficult to decompose naturally [11]. Among others, 2,4,6-trinitrophenol (TNP) is severely hazardous due to their high explosive nature, low safety coefficient, and widespread applications in fireworks, glass, matches, dyes, rocket fuels, and leather industries [12]. The effluents released by the 
industries into the environment containing TNP can results in severe environmental problems.

Metabolism of TNP develops picramic acid as a byproduct which shows the tenfold mutagenic activity compared to TNP [13]. Moreover, the carcinogenic activities of TNP can results in various health related issues such as headache, anemia, improper liver functions, skin irritation and so forth [14]. Hence, to decrease the adverse belongings of TNP on the atmosphere, it is reasonably necessary to evolve such kind of sensing material that is reliable, convenient and efficient, in order to detect NACs for the above concerns. Fluorescence-based chemical sensors; for instance, conjugated polymers [15], nanoparticles [16], MOF based fluorescent probes [17] are highly in demand for selective and sensitive detection of NACs.

On the flip side, the inorganic pollutant, hefty metal cations, are becoming a topical issue due to their high toxicity and bioaccumulation [18]. Among the essential heavy metal ions, detection of $\mathrm{Cr}^{3+}$ ion is also crucial since it significantly impacts the metabolism of carbohydrates, fats, nucleic acids, and proteins. $\mathrm{Cr}^{3+}$ is an essential trace element for human health. The insufficiency of $\mathrm{Cr}^{3+}$ might cause diabetes, cardiovascular diseases, and atherosclerosis [19]. However, $\mathrm{Cr}^{3+}$ in excess is still detrimental to human health, which can combine with DNA in the body and results in mutation or malignant cells [20]. Chromium is employed in industries on a large scale, for instance, steel fabrication, electroplating, tanning, paint manufacturing. Chromium waste is developed from burning coal, oxidative dyeing, cooling towers and sanitary landfills, and the use of corrosion inhibitors in water pipes [21]. The improper disposal of industrial waste containing chromium can pollute soil and water. Consequently, damaging the environment and human health. Therefore, it is essential to trace $\mathrm{Cr}^{3+}$ ions fastly and sensitively, as it is beneficial for the protection of environment. Hence, it remains a challenge to design and synthesize a bifunctional fluorescent MOFs to detect $\mathrm{Cr}^{3+}$ ion and TNP with rapid response time, high sensitivity, and selectivity in water. Following the points mentioned above, we designed and synthesized a 3-D Zn-MOF using $\mathrm{Zn}\left(\mathrm{NO}_{3}\right)_{2} \cdot 6 \mathrm{H}_{2} \mathrm{O}$ and planer pydc ligand, namely, $\left\{\left[\mathrm{Zn}_{2}(\text { pydc })_{2}(\mathrm{DMF})\right] \cdot 2 \mathrm{DMF}\right\}_{\mathrm{n}} \mathrm{Zn}-\mathrm{MOF}-1$, which was fortunately manufactured through a solvothermal method. The MOF was characterized using various spectroscopic technique and the definite structure was drawn by single crystal method. The Zn-MOF-1 can exploit as a dual fluorescent sensor to detect TNP and $\mathrm{Cr}^{3+}$ ion with a extremely low limit of detection in the aqueous phase. The better stability of Zn-MOF-1 can be the reason for its better sensing ability towards the hazardous substances in the water. By its good selectivity and sensitivity in sensing, it is competitive with current sensory materials.

\section{Experimental Protocols}

\subsection{Materials and methods}

The reagents used in this paper were analytical grade and procured from trade sources and used as received. pyridine-2,5-dicarboxylic acid (pydc), zinc nitrate hexahydrate, Nitroaromatic compounds (NACs), and the metal salts of nitrate were procured from Sigma-Aldrich Chemical Co. India. 


\section{Caution}

NACs are very reactive and explosives in nature and should be tested carefully and only in minute quantity. To prevent explosion, nitroaromatics were treated in safe manner.

\subsection{Physical Methods}

The solid state FTIR spectrum of Zn-MOF-1 within the range of $4000-400 \mathrm{~cm}^{-1}$ on the Perkin Elmer Model spectrum GX spectrophotometer. The Melting point of the compound was checked employing open capillary method. Further, the elemental analysis was obtained from Micro-Analytical Laboratory in CDRI, Lucknow, India. Perkin Elmer $\lambda-45$ UV visible spectrophotometer was used to record the electronic spectrum of the compound. The stock solution was made in $10^{-3} \mathrm{M}$ solution in aqueous phase by maintaining the $1 \mathrm{~cm}$ length of the cuvettes. Hitachi F-2700 spectrophotometer were used to record the emission spectra. "Miniflexll X-ray diffractometer" with Cu-Ka radiation was used to determine the PXRD patterns. The thermal behavior of MOF was checked using Shimadzu TGA-50H instrument with the heating of $20^{\circ} \mathrm{C} \mathrm{min}-1$ from $25^{\circ} \mathrm{C}$ to $800^{\circ} \mathrm{C}$.

\subsection{Single crystal X-ray data}

The Single Crystal X-ray diffraction of Zn-MOF-1 at $100 \mathrm{~K}$ was performed on Bruker SMART APEX CCD diffractometer. The graphite monochrome and Mo-Ka radiation $(\lambda=0.71073 \AA)$ was used for X-ray data collection [22]. Employing SAINT SOFTWARE, the reduction and integration of data were created [23]. The SADABS was used for empirical absorption correction [24] and XPREP was used to investigate the space group in Zn-MOF-1 [25]. The structure refinement was done by exploiting least-squares techniques on $\mathrm{F}^{2}$ by employing the OLEX-2 program package [26]. Furthermore, the non-hydrogen atoms were refined with anisotropic displacement parameters. The different hydrogen positions were fixed at calculated positions and refined isotopically. The CCDC reference numbers for Zn-MOF-1 is 2077312.

\subsection{Sensing Experiments}

In usual setup, the stock solution (1mM) of $\mathbf{Z n - M O F - 1}$ was prepared. The $3 \mathrm{ml}$ aqueous solution of $\mathbf{Z n}$ MOF-1 was placed in a $1 \mathrm{~cm}$ quartz cuvette on emission spectrophotometer. After excitation on $272 \mathrm{~nm}$ the fluorescence response was recorded. The incremental addition of nitro analytes and metal salts were added in the solution of Zn-MOF-1 and the emission spectra was observed. In the entire experiment the slit width of $2 \mathrm{~nm}$ was kept constant for both source and detector.

\subsection{Synthesis of $\left\{\left[\mathrm{Zn}_{2}(\mathrm{pydc})_{2}(\mathrm{DMF})\right] \cdot 2 \mathrm{DMF}\right\}_{\mathrm{n}}$}

The Zn-MOF-1 was synthesized by mixing $0.2 \mathrm{mmol}(0.033 \mathrm{gm})$ of $\mathrm{H}_{2}$ pydc, $0.2 \mathrm{mmol}(0.059 \mathrm{gm})$ of $\mathrm{Zn}\left(\mathrm{NO}_{3}\right)_{2} \cdot 6 \mathrm{H}_{2} \mathrm{O}$ in $3 \mathrm{~mL}$ of DMF. Then the solution was sealed in a Teflon- line stainless-steel autoclave and heated for $72 \mathrm{~h}$ at $100^{\circ} \mathrm{C}$. After that it was gradually cooled to room temperature over $12 \mathrm{~h}$. The small colorless round-shaped crystals were obtained in a yield of $48 \%$. 
Yield: $48 \%$, m.p. $315^{\circ} \mathrm{C}$, Anal.Calcd (\%) for $\mathrm{C}_{17} \mathrm{H}_{13} \mathrm{~N}_{3} \mathrm{O}_{9} \mathrm{Zn}_{2}$ : C $=52.92 ; \mathrm{H}=11.02 ; \mathrm{N}=5.51 ;$ Observed: $\mathrm{C}=$ 52.89; $\mathrm{H}=11.06 ; \mathrm{N}=5.54 . \mathrm{IR}\left(\mathrm{KBr}, \mathrm{cm}^{-1}\right)$ : 3438br, 2925m, 1614s, 1383s, $1281 \mathrm{w}, 763 \mathrm{~m}, 533 \mathrm{w}, 423 \mathrm{w}$.

\section{Results And Discussions \\ 3.1 Synthetic approach}

To uncover the chemistry behind the luminescent metal organic system in terms of its sensitive and selective sensing of hazardous substance in the water. We have employed our understanding and constructed a $\mathrm{Zn}$ (II)-based metal organic system which is better than other MOF based materials in terms of their sensing ability using fluorescence method. Fortunately, we have successfully synthesized a fluorescent Zn-MOF-1, by employing a planer pydc ligand which possess various coordination modes (Scheme 1). In this work we applied solvothermal method to synthesize Zn-MOF-1. We choose this method because of high solubility of precursors and thereby leads to the production of high-quality MOF crystals. The choice of solvent plays an important role as well. The solvent utilized in the fabrication process which may assist in binding with metal ions and thus act as a coordinating ligand or can behave as a guest solvent molecule in the environment of the complex [28]. Therefore, to look over the impact of coordination affinity towards the solvent, Junhua Luo's group carried out several reactions with distinct solvents such as DMF, DEF and DMA of $\mathrm{H}_{3} \mathrm{BPT}$ and $\mathrm{Cd}\left(\mathrm{NO}_{3}\right)_{2} \cdot 4 \mathrm{H}_{2} \mathrm{O}$ [29], among which some coordination architecture have been reported; for instance, $\left\{\left[\mathrm{Cd}_{3}(\mathrm{BPT})_{2}(\mathrm{DMF})_{2}\right] \cdot 2 \mathrm{H}_{2} \mathrm{O}\right\}$, which possess solvent as a coordinating agent, comparable to our designed MOF Zn-MOF-1 in which DMF act as both coordinating ligand and guest molecule in the lattice environment (Scheme 2).

\subsection{Structural explanation of Zn-MOF-1}

The Single crystal x-ray data (SCXRD) was used to analyze the exact structure of Zn-MOF-1. The SCXRD analysis revelas that Zn-MOF-1 crystallizes in a monoclinic system with P1 21/n1 space group. Table 1 enlisted the crystal data and different refinement parameters, and selected bond lengths, angles are given

in Table $\mathbf{S 1}$ of $\mathbf{Z n - M O F - 1 . ~ T h e ~ s t r u c t u r e ~ o f ~ Z n - M O F - 1 , ~ i . e . , ~}\left\{\left[\mathrm{Zn}_{2}(\text { pydc })_{2}(\mathrm{DMF})\right] \cdot 2 \mathrm{DMF}\right\}_{\mathrm{n}}$ is assembled by the repeating units of binuclear $\mathrm{Zn}$ (II) species. The labeled molecular structure of $\mathrm{Zn-MOF-1}$ is dispensed in Fig. 1. The interesting feature of $\mathrm{Zn-MOF-1}$ is that the two different $\mathrm{Zn}$ atoms, $\mathrm{Zn} 1$ and $\mathrm{Zn} 2$, exist in the structure in two different coordination environments. Each $\mathrm{Zn} 1$ atom is coordinated by one $\mathrm{N}$ - atom of pydc ligand, four O- atom from four different pydc ligands, and one O- atom of DMF ligand. Zn1 acquire distorted octahedral geometry (Fig. 2a) with 04, 09, N1, 01 form the equatorial plane, while 08 and 05 occupying the axial position. Few important bond angles that describe the order of distortion around $\mathrm{Zn} 1$ atom are found as 09-Zn1-04 $=166.81(6)^{\circ}, 01-\mathrm{Zn} 1-\mathrm{N} 1=170.13(7)^{\circ}, 05-\mathrm{Zn} 1-08=177.78(6)^{\circ}$, it supports the distorted octahedral geometry of Zn-MOF-1 [30]. On the other hand, similar coordination environment is found in $\mathrm{Zn} 2$ in terms of coordination to the pydc ligands. The coordination environment around $\mathrm{Zn} 2$ is filled by one $\mathrm{N}$ - atom of pydc ligand and four $\mathrm{O}$ - atoms of carboxylate moiety from four different pydc ligands with five coordination sites. The five-coordinated system can attain either triangular bipyramidal 
(tbp) geometry or square pyramidal (sq-py) geometry of $\mathrm{Zn}$ (II) ion. The Addison and co-workers introduced t parameter to distinguish between these two geometries [31]. The t parameter is in the range of $0-1$ and at the utmost values giving perfect sq-py or tbp geometry, respectively. The closer the value of $\mathrm{t}$ to 0 , the more relatable it is to sq-py geometry. We can calculate this parameter by applying the difference between the two largest coordination center angles and divide it by $60^{\circ}$. Our calculation shows that $\mathrm{Zn}(2)$ has a distorted sq-py geometry with $\mathrm{t}=(159.25-147.84) / 60=0.19$ (Fig. $2 \mathrm{~b}$ ). The quasi-square plane i.e., base is formed by $04,06,07$, and $N 2$. The top of the pyramid i.e., apex is formed by 02 . The important bond angles are obtained as 04-Zn2-N2 $=147.84(7)^{\circ}$ and 07-Zn2-06 $=159.25(7)^{\circ}$. The oxygen (04) of the same pydc ligand bridges the $Z n 1$ and $Z n 2$ atom. The bond angle between $Z n 2$ with its neighboring atom is N2-Zn2-04 $=147.84(7)^{\circ}, 07-Z n 2-04=100.38(6)^{\circ}, 06-Z n 2-07=159.25(7)^{\circ}, \mathrm{N} 2-Z n 2-02$ $=110.59(7)^{\circ}$; it also supports the distorted sq-py. For the sake of clarity, two uncoordinated DMF molecules in the lattice environment are squeezed. It should be noteworthy that, in Zn-MOF-1 pydc ligand exhibits two distinct coordination modes as shown in Fig. 2c. In mode-l, $\mu_{2}-\eta^{1}: \eta^{1}$ bridging mode is adopted by one carboxylate group. In contrast, the $\mathrm{O}$-atom of the second carboxylate group and $\mathrm{N}$-atom of pyridine adopts the $\mu_{1}-\eta^{1}: \eta^{1}$ chelating mode, and the other 0 -atom of the same carboxylate group is present in $\mu_{1}: \eta^{1}$ bridging mode, while in mode-Il pydc shows similar coordination modes as that of mode-I except for the second carboxylate group, which adopts $\mu_{1}-\eta^{1}: \eta^{2}$ bridging mode. In both cases, the whole pydc ligands act as a $\mu_{4}$ - bridge to bind four different $\mathrm{Zn}$ (II) atoms in adjoining chains, resulting in a threedimensional network structure (Fig. 3) [32, 33]. 
Table 1

Crystal structure and refinement data for Zn-MOF1.

\begin{tabular}{|c|c|}
\hline Compound & Zn-MOF-1 \\
\hline Empirical formula & $\mathrm{C}_{17} \mathrm{H}_{13} \mathrm{~N}_{3} \mathrm{O}_{9} \mathrm{Zn}_{2}$ \\
\hline Formula weight & 534.10 \\
\hline Crystal color & Colorless \\
\hline Temperature/K & $100(2)$ \\
\hline Crystal system & Monoclinic \\
\hline Space group & P $121 / n 1$ \\
\hline $\mathrm{a} / \AA ̊$ & $14.0774(10)$ \\
\hline$b / \AA$ & $12.1211(9)$ \\
\hline$c / \AA$ & $14.6325(10)$ \\
\hline $\mathrm{a} /^{\circ}$ & 90 \\
\hline$\beta /^{\circ}$ & $106.079(2)$ \\
\hline $\mathrm{Y} /{ }^{\circ}$ & 90 \\
\hline Volume $/ \AA^{3}$ & 2399.1(3) \\
\hline Z & 4 \\
\hline$\rho_{\text {calc }} \mathrm{g} / \mathrm{cm}^{3}$ & 1.4786 \\
\hline$\mu / \mathrm{mm}^{-1}$ & 2.047 \\
\hline$F(000)$ & 1075.0356 \\
\hline Crystal size $/ \mathrm{mm}^{3}$ & 0.37 \\
\hline Radiation & Mo-Ka \\
\hline Independent reflections & 5975 \\
\hline $\mathrm{WR}_{2}$ (all) & 0.0896 \\
\hline $\mathrm{WR}_{2}$ & 0.0841 \\
\hline Final R Indexes $[I>=2 \sigma(I)]$ & 0.0294 \\
\hline Final R indexe(all data) & 0.0363 \\
\hline$\Theta_{\min }$ & 2.18 \\
\hline
\end{tabular}




\begin{tabular}{|ll|}
\hline Compound & Zn-MOF-1 \\
\hline$\Theta_{\max }$ & 21.91 \\
\hline
\end{tabular}

\subsection{FTIR, UV-Visible, PXRD and TG analysis of Zn-MOF-1}

FT-IR spectrum of Zn-MOF-1 is given in Fig. 4a. The broadband observed at $3438 \mathrm{~cm}^{-1}$ can be consigned to the $v(\mathrm{C}-\mathrm{H})$ pyridyl ring stretching vibration. Again, the weak band at $2925 \mathrm{~cm}^{-1}$ is characteristic of the $\mathrm{v}(\mathrm{C}-\mathrm{H})$ vibrations of the coordinated DMF molecule. The absence of characteristics band at around 1700 $\mathrm{cm}^{-1}$ which is assignable to $-\mathrm{COOH}$ groups designate that all carboxyl groups is completely deprotonated in Zn-MOF-1 upon reaction with metal ion [34]. For Zn-MOF-1, the two strong bands at 1614 $\mathrm{cm}^{-1}$ and $1383 \mathrm{~cm}^{-1}$ (Scheme S1), corresponding to the stretching vibrations of asymmetric and symmetric carboxyl groups, respectively [35]. The weak band at $1281 \mathrm{~cm}^{-1}$ are assigned to $\mathrm{v}(\mathrm{C}-\mathrm{O})$ vibrations and the absorption band observed at $763 \mathrm{~cm}^{-1}$ are due to $\delta(0-\mathrm{C}-0)$ vibrations of the pydc [36]. The absorption at $533 \mathrm{~cm}^{-1}$ corresponds to $\mathrm{v}(\mathrm{Zn}-0)$ vibration, and the band in weak intensity at $423 \mathrm{~cm}^{-}$

${ }^{1}$ consigned to the $\mathrm{v}(\mathrm{Zn}-\mathrm{N})$ vibration [37]. The infrared spectra of Zn-MOF-1 are compatible with its structural features as resolved by SCXRD. The absorption spectrum of Zn-MOF-1 exhibited well resolved absorption band at $272 \mathrm{~nm}$ which is assignable to intraligand $\left(n \rightarrow \pi^{*}, \pi \rightarrow \pi^{*}\right)$ transition. Zn-MOF-1 doesn't show any $d-d$ transition due to the closed shell $d^{10}$ configuration as illustrated in Fig. $4 \mathrm{~b}$.

Thermal gravimetric analysis (TGA) was performed in presence of $\mathrm{N}_{2}$ atmosphere, to inspect the thermal disintegration of Zn-MOF-1. The model pattern of TG curve exhibits two decomposition steps as shown in Fig. 4c. In very first step, TG curve displays the weight loss of $27.36 \%$ at $380^{\circ} \mathrm{C}$, corroborates the loss of two uncoordinated DMF in the lattice (Calc.: $27.50 \%$ ), while in case of second step it exhibits weight loss of $76.26 \%$ at $550^{\circ} \mathrm{C}$ which is corresponds to the loss of one coordinated DMF and two units of pydc ligand (Calc.: $76.52 \%$ ). Then, no changes were found from $550^{\circ} \mathrm{C}-800^{\circ} \mathrm{C}$ and the final product left may be the metal residue. Additionally, the PXRD investigation were done on Zn-MOF-1 to affirm the phase purity of the sample. The simulated and as-synthesized patterns are quite similar to each other as display in Fig. 5. The PXRD patterns of Zn-MOF-1 was also recorded before and after immersing the sample in water for $24 \mathrm{~h}$. Both the pattern is almost identical confirming the robust nature and structural integrity of Zn-MOF-1 [38].

\subsection{Fluorescence ability of Zn-MOF-1}

After excitation at $272 \mathrm{~nm}$ the emission spectrum of Zn-MOF-1 in solution state shows a sharp intense peak at $385 \mathrm{~nm}$ Fig. $4 \mathrm{~b}$. The $\mathrm{Zn}(\mathrm{II})$ ions possess $\mathrm{d}^{10}$ configuration, thus it is not easily get oxidize or reduce, it indicates the absence of MLCT and LMCT behavior of Zn-MOF-1 [39]. Consequently, the band of Zn-MOF-1 can be consigned to intraligand fluorescence emissions. Additionally, to check out either the emission spectra are based only on ligand or depend on the entire moiety of Zn-MOF-1, the emission spectra of free ligand pydc upon excitation at $270 \mathrm{~nm}$ shows a moderate peat at $345 \mathrm{~nm}$ (Fig. 6.). 
Accordingly, it could be deduced that intense emission spectrum of Zn-MOF-1 doesn't depend merely on ligand moiety instead its entire moiety is the reason behind the intense emission, thus Zn-MOF-1 is a fluorescent material. This inspire us to explore its potential application in the field of nitroaromatic compounds sensitive sensing and some other vital and lethal metal ions.

\subsection{Selective and sensitive recognition of TNP}

In order to understand the potential application of Zn-MOF-1 to sense a minute amount of nitro explosives, fluorescence-quenching titration was implemented by the incremental addition of nitro analytes to $\mathrm{Zn}-\mathrm{MOF}-1$ in $\mathrm{H}_{2} \mathrm{O}$. For fluorescence sensing experiment, specified nitro aromatics compounds were selected: TNP (2,4,6-trinitrophenol), ONP (2-nitrophenol), ONA (2-nitroaniline), MNA (3-nitroaniline), MDNB (1,3-dinitrobenzene). The fluorescence intensity of Zn-MOF-1 had a little effect on incremental addition of ONA, MNA, and MDNB (Fig. S1-S2, ESI), except for ONP, which shows considerable quenching behavior (Fig. S2b, ESI). Impressively, Zn-MOF-1 showed good sensing behavior and high fluorescence quenching (95\%) for TNP on incremental addition of $10^{-3} \mathrm{M}(50 \mu \mathrm{L})$ analyte (Fig. 7b). The marvelous fluorescence quenching of $54 \%$ was observed at a very little concentration of TNP i.e., $0.12 \mathrm{ppb}$ in $\mathrm{H}_{2} \mathrm{O}$ (details in ESI). As far as we know, Zn-MOF-1 shows the highest quenching efficiency as compare to that of reported MOFs [40] for sensitive sensing of TNP employing Zn-MOF-1 (Table 2). The quenching efficiencies of the selected analytes in descending order are as follows: TNP $(95 \%)>$ ONP $(87 \%)>$ MDNB $(50 \%)>$ MNA $(47 \%)>$ ONA (41\%) (Fig. 7d). This indicates a strong interaction between TNP and Zn-MOF-1 with a detection limit of $0.12 \mathrm{ppb}$. This signify that Zn-MOF-1 exihibits super sensitivity for TNP detection in the aquatic phase, which is vital for environmental application purpose [41]. Using Stern-Volmer (S-V) equation [42] (details in ESI) we analyzed the quenching efficiencies of all the analytes to discover the cause behind the quenching mechanism for the selective and sensitive sensing of TNP. The plots with TNP and ONP show a linear increase at low concentration, which deviates from linearity and turn in an upwards direction with increasing concentrations. Whereas the other nitro aromatic analytes showed only linear trends in the S-V plots (Fig. 7c). A 3-D model of the S-V plots of Zn-MOF-1 for different nitro analytes in water is shown (Fig. 8). On the other hand the linear fitting plot $\left(R^{2}=0.97\right)$ displays the significant quenching ability of Zn-MOF-1 towards TNP in water with Stern-Volmer quenching constant $\mathrm{K}_{\mathrm{sv}}$ of $2.1 \times 10^{8}$ for TNP and among the reported MOFs this is the highest value obtained for selective detection of TNP till date [43]. Two possible mechanisms for quenching the fluorescence intensity of electron-rich Zn-MOF-1 by electron-deficient TNP can be suggested on the basis of steady-state fluorescence measurements. It includes (1) photo-induced electron transfer (PET) mechanism and (2) fluorescence resonance energy transfer (FRET) mechanism. The highly selective detection of TNP by ZnMOF-1 might be assigned to PET mechanism. In general, the lowest unoccupied MOs (LUMO) of nitro analyte (electron-deficient) lies between the valence band (VB) and conduction band (CB) of the MOFs [44]. Upon excitation, the excited electron resided in the CB of Zn-MOF-1 can easily transfer to the LUMO of electron-deficient analytes. Therefore, there is quenching in fluorescence intensity of Zn-MOF-1. However, in case of analytes having electron-rich systems, the LUMO lies above the CB of the MOFs, excited-state electrons from the LUMO of the analytes will be transferred to the CB of the MOFs which 
leads to the enrichment of the fluorescence intensity. This was well elaborated by various research articles published in the literature. Mukul et al. reported the insight of PET mechanism by employing the theoretical calculations such as DFT. In this article the 2,6-pyridine dicarboxylic acid ( $\left.\mathrm{pda}^{2-}\right)$ ligand has been employed for the formation of three Ln-based MOF materials. The DFT calculations can be employed to calculate the HOMO-LUMO energy gap. The energy gap calculated using DFT does not in good agreement of PET mechanism which means that the PET mechanism is not the solely mechanism responsible for the sensitive and selective detection of TNP. This was also well established in the few other articles in which author used DFT calculations for confirming the mechanism associated with the sensitive and selective detection of nitro analytes [45]. Though, the fluorescence quenching for all other nitro analytes is not in line with their LUMO energy trend except TNP, this indicate that there were some other reasons for drastic quenching which synchronized with electron transfer. The FRET mechanism transfer resonance energy from fluorophore to non-emissive analyte. The absorption bands of the nitro analytes must overlap effectively with the emission band of the fluorophore [46]. To examine this, the normalized emission spectra and UV spectra of the Zn-MOF-1 and for all the nitro analytes were recorded. The overlap graph was plotted between the relative intensity and the wavelength. As shown in Fig. 9 it is found that TNP showed maximum overlap with the fluorescence emission spectrum of Zn-MOF-1. On the other hand, it was relatively less or almost no overlap was found for other nitro analytes. This is in plausible accordance with the high quenching efficiency observed for TNP as compare to other nitro analytes. Consequently, it is eminent in TNP that it involves both electron and energy-transfer mechanisms where as only electron-transfer mechanisms could employ by other nitro analytes. Thereby collaborative involvement of such processes, viz. PET and FRET, that may lead to the enhancement of quenching efficiency of TNP with a very good detection-sensitivity limit. Furthermore, with the help of Xray structure it was well established that there is no evidence of porosity in the structure of Zn-MOF-1. Hence the trapping of nitroaromatic analytes on the pores of Zn-MOF-1 was nullified. Moreover, the identical PXRD patterns of Zn-MOF-1, before and after soaking in the solution of TNP for 24h specify that there is no evidence of degradation of Zn-MOF-1 after immersing it in TNP as specified in Fig. 5 which authenticate the robust nature and stability of the MOF. The particular Zn-MOF-1 can be used for different cycle of fluorescence sensing and to trace the TNP in water.

\subsection{Selective and sensitive detection of $\mathrm{Cr}^{3+}$}

To check the sensing behavior of $\mathrm{Zn}$-MOF-1, we prepared stock solution of different metal ions $\mathrm{M}\left(\mathrm{NO}_{3}\right)_{\mathrm{x}}($ $\left.\mathrm{M}=\mathrm{Na}^{+}, \mathrm{K}^{+}, \mathrm{Ba}^{2+}, \mathrm{Sr}^{2+}, \mathrm{Mn}^{2+}, \mathrm{Co}^{2+}, \mathrm{Ca}^{2+}, \mathrm{Zn}^{2+}, \mathrm{Mg}^{2+}, \mathrm{Sn}^{2+}, \mathrm{Cd}^{2+}, \mathrm{Pb}^{2+}, \mathrm{Cu}^{2+}, \mathrm{Hg}^{2+}, \mathrm{Cr}^{3+}, \mathrm{Cr}^{6+}\right)$ in aqueous phase and gradually it was added to the aqueous solution of Zn-MOF-1 and then the fluorescence spectra were recorded. It was detected that the fluorescence intensity was moderately enhanced in $\mathrm{Zn}^{2+}, \mathrm{Sr}^{2+}$, $\mathrm{Na}^{+}, \mathrm{Mn}^{2+}, \mathrm{Co}^{2+}, \mathrm{Ca}^{2+}, \mathrm{Mg}^{2+}, \mathrm{Cr}^{6+}, \mathrm{Ba}^{2+}, \mathrm{Sn}^{2+}, \mathrm{Cd}^{2+}, \mathrm{Pb}^{2+}, \mathrm{Cu}^{2+}$, and $\mathrm{K}^{+}$ions except in the case of $\mathrm{Hg}^{2+}$ ion which shows a mild quenching behavior. As shown in Fig. 10a, a notable quenching was detected by $\mathrm{Cr}^{3+}$ ion. The quenching efficiency was calculated to be $43 \%$ after the addition of only $10^{-3} \mathrm{M}(50 \mu \mathrm{l})$ of $\mathrm{Cr}^{3+}$ ions. The quenching efficiency affiliated with $\mathrm{Hg}^{2+}$ ions was $11 \%$ which is the highest value in 
comparative to other metal ions, Fig. 11a. This suggested that Zn-MOF-1 can be used selectively for the sensing of $\mathrm{Cr}^{3+}$ ions in an aqueous solution. From the practical point of view selectivity in sensing is a very crucial factor in biological and environmental systems where numerous metal ions may coexist. To further explore the sensitivity of $\mathrm{Zn-MOF-1}$ as a $\mathrm{Cr}^{3+}$ sensor the fluorescence quenching titrations experiment were done by gradual addition of different concentrations of $\mathrm{Cr}^{3+}$ ions. Fluorescence intensity of Zn-MOF-1 moderately decreased as the concentration of $\mathrm{Cr}^{3+}$ ion increases (Fig. 10b). Moreover, the Stern-Volmer constant, $\mathrm{K}_{\mathrm{sv}}=1.46 \times 10^{7}$ obtained from linear fitting of the plot $\left(\mathrm{R}^{2}=0.93\right)$ (details in ESI). Zn-MOF-1 exhibits the highest $\mathrm{K}_{\mathrm{sv}}$ value reported for selective and sensitive sensing of $\mathrm{Cr}^{3+}$ ion (Table 3). Competitive experiments were carried out to explore the selectivity for sensing $\mathrm{Cr}^{3+}$ ions over various interfering metal cations. As shown in Fig. 11b, upon the addition of $\mathrm{Cr}^{3+}$ ions to the mixture of Zn-MOF-1 and other interfering cations, it was observed that the fluorescence is remarkably quenched, indicating that Zn-MOF-1 can selectively and effectively detect $\mathrm{Cr}^{3+}$ ion. It was illustrating that $\mathrm{Cr}^{3+}$ ions can still be sensed when it is accompanied by other metal ions.

As reported in previous literature, the quenching mechanisms of the fluorescent MOFs of various metal ions mainly attributed to (i) the structure of MOF being collapsed by the metal ions; (ii) exchange of cations between the metal centers of MOFs and the objective cations; (iii) competetive absorption and fluorescence resonance energy transfer (FRET) between fluorophores in MOFs and incoming metal ions [47]. The following experiments were performed to elucidate the mechanism of Zn-MOF-1 as a sensor towards $\mathrm{Cr}^{3+}$ ion through quenching effects. PXRD patterns of Zn-MOF-1 were recorded before and after soaking in the solution of $\mathrm{Cr}^{3+}$ for $24 \mathrm{~h}$ to authenticate the extra stability of Zn-MOF-1 (Fig. 5). Secondly, Considering the neutral framework of Zn-MOF-1, it is not possible that the fluorescence sensing results from cations exchange. As shown in Fig. 12 the UV-visible absorption spectrum of various metal cations was measured, which showed that solely $\mathrm{Cr}^{3+}$ significantly overlapped with the excitation band of $\mathbf{Z n}$ MOF-1, which suggested that the competitive energy absorption between $\mathrm{Zn-MOF-1} \mathrm{excitation} \mathrm{and} \mathrm{Cr}^{3+}$ ion absorption probably happened and resulted in fluorescence quenching of Zn-MOF-1. Therefore, it can be deduced that the fluorescence quenching mechanism of Zn-MOF-1 for sensing of $\mathrm{Cr}^{3+}$ can be attributed to both competitive energy absorption and FRET.

To calculate the detection limit, TNP $\left(5-50 \mu \mathrm{l}, 1 \mathrm{mM}\right.$ stock solution) and $\mathrm{Cr}^{3+}(50-300 \mu \mathrm{l}, 1 \mathrm{mM}$ stock solution) were added to Zn-MOF-1, and noted the equivalent fluorescent intensities by plotting the graph between fluorescence intensity and increasing concentration of the analyte, then calculated the slope $(\mathrm{m})$ of the analogue graph (Fig S3, S4, ESI). Moreover, from five blank measurements standard deviation ( $\sigma$ ) was also calculated of Zn-MOF-1 (Table S2, S3, S4, ESI), and the detection limit of Zn-MOF-1 was calculated by employing the formula: Detection limit $=(3 \sigma / m)$. TNP has detection limit of $0.12 \mathrm{ppb}$ while $0.62 \mathrm{ppb}$ was found in the case of $\mathrm{Cr}^{3+}$. 
Table 2

Selected MOF with TNP sensing and their $\mathrm{K}_{\mathrm{sV}}$ Value.

\begin{tabular}{|lllll|}
\hline Fluorescent sensing Materials & Analyte & $\mathrm{Ksv}\left(\mathrm{M}^{-1}\right)$ & Detection limit & Ref. \\
\hline$\left[\mathrm{Zr}_{6} \mathrm{O}_{4}(\mathrm{OH})_{4}(\mathrm{BTDB})_{6}\right] \cdot 8 \mathrm{H}_{2} \mathrm{O} \cdot 6 \mathrm{DMF}$ & $\mathrm{TNP}$ & $2.49 \times 10^{4}$ & $1.63 \mathrm{ppm}$ & 48 \\
\hline$\left[\mathrm{Eu}_{2}(\mathrm{~L})_{2}(\mathrm{DMA})_{2}\right] \mathrm{n} \cdot \mathrm{nH}_{2} \mathrm{O}$ & $\mathrm{TNP}$ & $3.58 \times 10^{4}$ & $4.66 \times 10^{-4} \mathrm{mM}$ & 49 \\
\hline $\mathrm{Bio}-\mathrm{MOF}-1$ & $\mathrm{TNP}$ & $4.6 \times 10^{4}$ & $2.9 \mathrm{ppb}$ & 50 \\
\hline$[\mathrm{Tb}(1,3,5-\mathrm{BTC})]$ & $\mathrm{TNP}$ & $3.41 \times 10^{4}$ & $8.1 \times 10^{-8} \mathrm{M}$ & 51 \\
\hline UiO-68@NH$H_{2}$ & $\mathrm{TNP}$ & $5.8 \times 10^{4}$ & $0.4 \mathrm{ppm}$ & 52 \\
\hline Y-MOF:Eu & $\mathrm{TNP}$ & $3.21 \times 10^{4}$ & $4 \mu \mathrm{M}$ & 53 \\
\hline Y-MOF:Tb & TNP & $3.1910^{4}$ & $6.5 \mu \mathrm{M}$ & 53 \\
\hline Zn-MOF-1 & TNP & $2.1 \times 10^{8}$ & $0.12 \mathrm{ppb}$ & This Work \\
\hline
\end{tabular}

Table 3

Selected MOF with $\mathrm{Cr}^{3+}$ sensing and their $\mathrm{K}_{\mathrm{sv}}$ Value.

\begin{tabular}{|lllll|}
\hline Fluorescent sensing Materials & Analyte & $\mathrm{Ksv}\left(\mathrm{M}^{-1}\right)$ & $\begin{array}{l}\text { Detection } \\
\text { limit }\end{array}$ & Ref. \\
\hline$\left[\mathrm{Zn} \mathrm{T}_{2}(\mathrm{TCBPDC})_{0.5}\left(\mathrm{H}_{2} \mathrm{O}\right)_{2}\right]_{\mathrm{n}}$ & $\mathrm{Cr}^{3+}$ & $7.32 \times 10^{3}$ & $0.56 \mathrm{ppm}$ & 54 \\
\hline$\left[\mathrm{Eu}_{2}(\mathrm{tpbpc})_{4} \cdot \mathrm{CO}_{3} \cdot 4 \mathrm{H}_{2} \mathrm{O}\right] \cdot \mathrm{DMF} \cdot$ solvent & $\mathrm{Cr}^{3+}$ & $5.14 \times 10^{2}$ & $3.64 \mathrm{ppm}$ & 55 \\
\hline$\left[\mathrm{Tb}(\mathrm{hfac})_{3}(\mathrm{NITPh}-\mathrm{Pa})_{2}\right]\left[0.5 \mathrm{CH}_{3}\left(\mathrm{CH}_{2}\right)_{5} \mathrm{CH}_{3}\right]$ & $\mathrm{Cr}^{3+}$ & 1483.82 & $2.34 \mathrm{ppm}$ & 56 \\
\hline $\mathrm{Zn}(\mathrm{tbda})]_{\mathrm{n}}$ & $\mathrm{Cr}^{3+}$ & $2.68 \times 10^{3}$ & $9.36 \mathrm{ppm}$ & 57 \\
\hline $\begin{array}{l}\left.\mathrm{CH}_{3}-\mathrm{dpb}\right]_{2}\left[\mathrm{Mg}_{3}(1,4 \mathrm{NDC})_{4}\left(\mathrm{HH}_{2} \mathrm{O}\right)_{2}\left(\mathrm{CH}_{3} \mathrm{OH}\right)\right. \\
\left.\left(\mathrm{H}_{2} \mathrm{O}\right)\right] \cdot 1.5 \mathrm{H}_{2} \mathrm{O}\end{array}$ & $\mathrm{Cr}^{3+}$ & $0.15 \times 10^{5}$ & $960 \mathrm{ppm}$ & 58 \\
\hline $\mathrm{Zn} \mathrm{n}_{3}(\mathrm{bpdc})_{2}(\mathrm{pdc})(\mathrm{DMF}) \cdot 6 \mathrm{DMF}$ & & & & \\
\hline $\mathrm{Zn}-\mathrm{MOF}-1$ & $\mathrm{Cr}^{3+}$ & $3.870 \times 10^{3}$ & $25.1 \mathrm{ppm}$ & 59 \\
\hline
\end{tabular}

\section{Conclusion}

In summary, we successfully constructed and structurally characterized a fluorescent 3D Zn-MOF-1. The MOF was synthesized to explore sensing ability towards different hazardous substances. Using slow evaporation method, the MOF was synthesized and with the help SCXRD the exact structure of MOF was confirmed. The PXRD pattern and TG analysis reveals the bulk purity as well as thermal stability of the 
Zn-MOF-1. Significantly, Zn-MOF-1 displays strong fluorescence emission and can be used as a potential fluorescent probe for efficiently detecting TNP and $\mathrm{Cr}^{3+}$ ion in aqueous solution. The detection limit of $\mathrm{Zn}$ MOF-1 towards TNP and $\mathrm{Cr}^{3+}$ were calculated with the values of $0.12 \mathrm{ppb}$ and $0.62 \mathrm{ppb}$, respectively. Furthermore, the possible fluorescence quenching mechanism of $\mathrm{Zn}-\mathrm{MOF}-1 \mathrm{for}$ TNP and $\mathrm{Cr}^{3+}$ were also elucidated. Consequently, the present study revealed that fluorescent Zn-MOF-1 can be rationally constructed and scrutinized as a potential fluorescent sensing material for multi-functional applications in future endeavors.

\section{References}

1. M.S. Khan, M. Khalid, M. Shahid, Polyhedron 196, 114984 (2021)

2. K.M.L. Taylor-Pashow, J.D. Rocca, Z.G. Xie, S. Tran, W. Lin, J. Am. Chem. Soc. 131, 14261 (2009).

3. L. Ma, J.M. Falkowski, C. Abney, W. Lin, Nat. Chem. 2, 838 (2010).

4. M.S. Khan, M. Khalid, M. Shahid, Mater. Adv. 1, 1575 (2020).

5. R. Banerjee, H. Furukawa, D. Britt, C. Knobler, M. O'Keeffe, O.M. Yaghi, J. Am. Chem. Soc. 131, 3875 (2009).

6. K. Iman, M.N. Ahamad, A. Ansari, H. A. Saleh, M. S. Khan, M. Ahmad, M. Shahid RSC Advances 11 16881 (2021).

7. L.E. Kreno, K. Leong, O.K. Farha, M. Allendorf, R.P. Van Duyne, J.T. Hupp, Chem. Rev. 112, 1105 (2012).

8. X.Y. Xu, B. Yan, ACS Appl. Mater. Interfaces 7, 721 (2015).

9. L. Zhang, Z. Kang, X. Xin, D. Sun, CrystEngComm 18, 193 (2016).

10. L.E. Kreno, K. Leong, O.K. Farha, M. Allendorf, R.P.V. Duyne, J.T. Hupp, Chem. Rev. 112, 1105 (2012).

11. Z.S. Qin, W.W. Dong, J. Zhao, Y.P. Wu, Q.C. Zhang, D.S. Li, Inorg. Chem. Front. 5, 120 (2018).

12. S.S. Nagarkar, A.V. Desai, S.K. Ghosh, Chem. Commun. 50, 8915 (2014).

13. K.M. Wollin, H.H. Dieter, Arch. Environ. Contam. Toxicol. 49, 18 (2005).

14. D. Udhayakumari, S. Velmathi, P. Venkatesan, S.P. Wu, Anal. Methods 7, 1161, (2015).

15. Y. Salinas, R. Martinez-Manez, M.D. Marcos, F. Sancenon, A.M. Costero, M. Parraad, S. Gil, Chem. Soc. Rev. 41, 1261 (2012).

16. D. Gao, Z. Wang, B. Liu, L. Ni, M. Wu, Z. Zhang, Anal. Chem. 80, 8545 (2008). 
17. J. Lei, R. Qian, P. Ling, L. Cui, H. Ju, Trends Anal. Chem. 58, 71 (2014).

18. L. You, D.J. Zha, E.V. Anslyn, Chem. Rev. 115, 7840 (2015).

19. T. Yang, X.Y. Zhang, X.X. Zhang, M.L. Chen, J.H. Wang, ACS Appl. Mater. Interfaces 7, 21287 (2015).

20. E.A. Katayev, Y.A. Ustynyuk, J. L. Sessler, Coord. Chem. Rev. 250, 3004 (2006).

21. K.S. Subramanian, Anal. Chem. 60, 11 (1988).

22. J. A. Ibers, W.C. Hamilton, International Tables for X-ray Crystallography, Kynoch Press, Birmingham, England, 1974, vol. IV. 26 SMART \& SAINT Software Reference manuals, Version 6.45, Bruker Analytical Xray Systems, Inc., Madison, WI, 2003.

23. SMART \& SAINT, Software Reference Manuals, Version 6.45 (Bruker Analytical X-ray Systems, Inc., Madison, (2003).

24. W.P. Wu, J. Wu, J.Q. Liu, M. Trivedi, A. Kumar, RSC Adv. 7, 54522 (2017).

25. A.W. Addison, T.N. Rao, J. Reedijk, J. Van Rijn, G.C. Verschoor, J. Chem. Soc. Dalton Trans. 1349 (1984).

26. O.V. Dolomanov, L.J. Bourhis, R.J. Gildea, J.A.K. Howard, H. Puschmann, J. Appl. Cryst. 42, 339 (2009)

(b) L.J. Bourhis, O.V. Dolomanov, R.J. Gildea, J.A.K. Howard, H. Puschmann, Acta Cryst. 71, 59 (2015).

27. Q.B. BO, J.J. Pang, H.Y. Wang, C.H. Fan, Z.W. Zhang, Inorg. Chim. Acta 428, 170 (2015).

28. A.A. Yakovenko, Z. Wei, M. Wriedt, J.R. Li, G.J. Halder, H.C. Zhou, Cryst. Growth Des. 14, 5397 (2014).

29. L. Li, S. Wang, T. Chen, Z. Sun, J. Luo, M. Hong, Cryst. Growth Des. 12, 4109 (2012).

30. S. Kamal, M. Khalid, M.S. Khan, M. Shahid, M. Ashafaq, I. Mantasha, M.S. Ahmad, M. Ahmad, M. Faizan, S. Ahmad, Inorg. Chim. Acta 512, 119872 (2020).

31. A.W. Addison, T.N. Rao, J. Reedijk, J. Van Rijn, G.C. Verschoor, J. Chem. Soc. Dalton Trans. 1349 (1984).

32. M.S. Khan, M. Khalid, M.S. Ahmad, S. Kamal, M. Shahid, M. Ahmad, J. Biomol. Struct. Dyn. (2020). DOI: 10.1080/07391102.2021.1924263.

33. M.S. Khan, M. Khalid, M.S. Ahmad, M. Ahmad, M. Ashafaq, R. Uddin, R. Arif, M. Shahid, J. Mol. Struct. 889, 1175 (2019).

34. M.S. Ahmad, M. Khalid, M.S. Khan, M. Shahid, M. Ahmad, J. Struct. Chem. 61, 533 (2020).

35. M. S. Khan, M. Khalid, M. S. Ahmad, M. Shahid, M. Ahmad, Res. Chem. Intermed., 462985 (2020). 
36. A.T. Çolak, O.Z. Yeşilel, O. Büyükgüngör, J. Mol. Struct. 68, 991 (2011).

37. M. S. Khan, M. U. Hayat, M. Khanam, H. Saeed, M. Owais, M. Khalid, M. Shahid, M. Ahmad J. Biomol. Struct. Dyn., 39, 4037 (2021).

38. M.S. Khan, M. Khalid, M. Shahid, RSC Adv. 11, 2630 (2021).

39. L. Wen, Z. Lu, J. Lin, Z. Tian, H. Zhu, Q. Meng, Cryst. Growth Des. 7, 93 (2007).

40. Z. Hu, B.J. Deibert, J. Li, Chem. Soc. Rev. 43, 5815 (2014).

41. D. Li, J. Liu, R.T.K. Kwok, Z. Liang, B.Z. Tang, J. Yu, Chem. Commun. 48, 7167 (2012).

42. E. Barea, C. Montoro, J.A.R. Navarro, Chem. Soc. Rev. 43, 5419 (2014).

43. Z. Hu, B.J. Deibert, J. Li, Chem. Soc. Rev. 43, 5815 (2014).

44. M.S. Khan, M. Khalid, M.S. Ahmad, M. Shahid, M. Ahmad, Dalton Trans. 48, 12918 (2019).

45. (a) M. Raizada, F. Sama, M. Ashafaq, M. Shahid, M. Ahmad, Z.A. Siddiqi, J. Mater. Chem. C 5, 9315 (2017); (b) M. Ashafaq, M. Khalid, M. Raizada, M. S. Ahmad, M. S. Khan, M. Shahid, M. Ahmad, J. Inorg. Organomet. Poly Mat.. 30, 4496 (2020).

46. J. Wang, J. Mei, W. Yuan, P. Lu, A. Qin, J. Sun, Y. Ma, B.Z. Tang, J. Mater. Chem. 21, 4056 (2011).

47. (a) S. Dang, E. Ma, Z.M. Sun, H. Zhang, J. Mater. Chem. 22, 16920 (2012); (b) Q. Tang, S. Liu, Y. Liu, J. Miao, S. Li, L. Zhang, Z. Shi, Z. Zheng, Inorg. Chem. 52, 2799 (2013); (c) S.T. Zhang, J. Yang, H. Wu, Y.Y. Liu, J.F. Ma, Eur. J. Chem. 21, 15806 (2015); (d) C.X. Yang, H.B. Ren, X.P. Yan, Anal. Chem. 85, 7441 (2013).

48. S.K. Mostakim, S, Biswas, CrystEngComm 18, 3104 (2016).

49. X. Wang, P. Yan, Y. Li, G. An, X. Yao, G. Li, Cryst. Growth Des. 17, 2178 (2017).

50. B. Joarder, A.V. Desai, P. Samanta, S. Mukherjee, S.K. Ghosh, Chem. Eur. J. 21, 965 (2015).

51. J.D. Xiao, L.G. Qiu, F. Ke, Y.P. Yuan, G.S. Xu, Y.M. Wang, X. Jiang, J. Mater. Chem. A. 1, 8745 (2013).

52. S.S. Nagarkar, A.V. Desai, P. Samanta, S.K. Ghosh, Dalton Trans. 44, 15175 (2015).

53. D.K. Singha, P. Majee, S.K. Mondal, P. Mahata ,RSC Adv. 5, 102076 (2015).

54. J. Ma, Q. Guo, T. Ma, L. Zhou, J. Yang, Q.F. Yang, New J. Chem. 44, 7293 (2020).

55. J. Liu, G. Ji, J. Xiao, Z. Liu, Inorg. Chem. 56, 4197 (2017).

56. S.L. Yang, R.R. Wang, X.J. Jin, C.X. Zhang, Q.L. Wang, Polyhedron 144, 101 (2018). 
57. X. Liang, Y. Jia, Z. Zhan, M. Hu, Appl. Organomet. Chem. 33, (2019).

58. Z.F. Wu' L.K. Gong' X.Y. Huang, ${ }^{*}$ Inorg. Chem. 56, 7397 (2017).

59. X. Meng, M.J. Wei, H.N. Wang, H.Y. Zang, Z.Y. Zhou, Dalton Trans. 47, 1383 (2018).

\section{Figures}

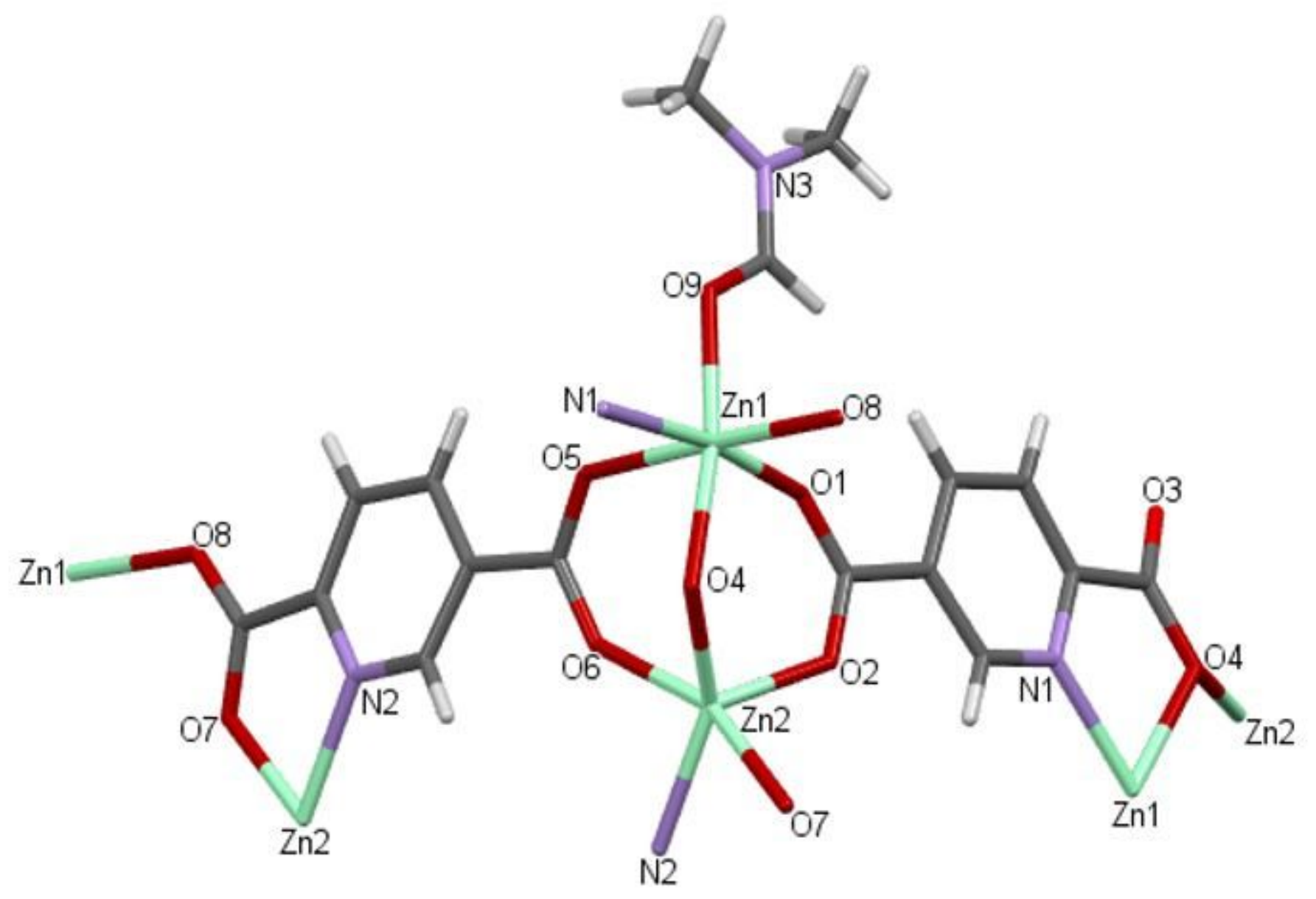

Figure 1

Labelled Molecular structure of Zn-MOF-1. 


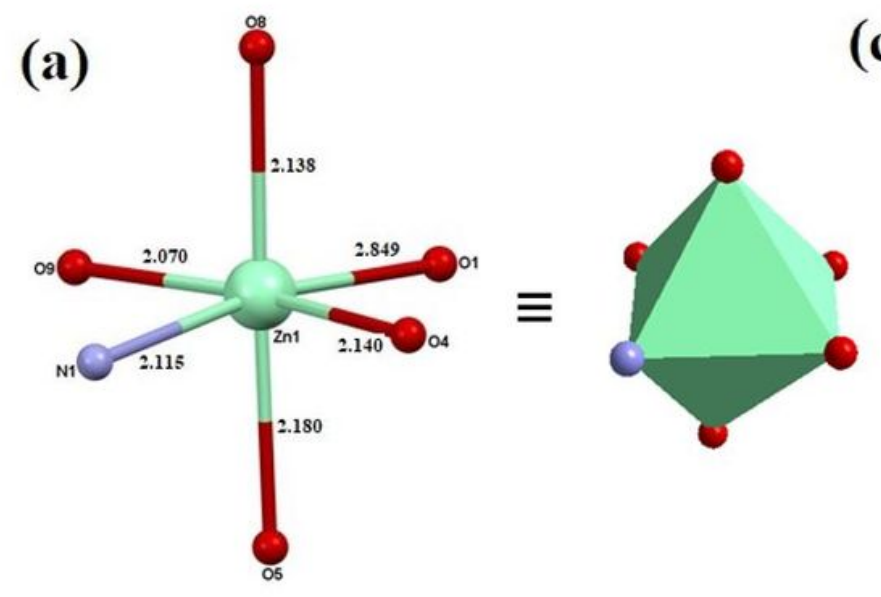

(c)
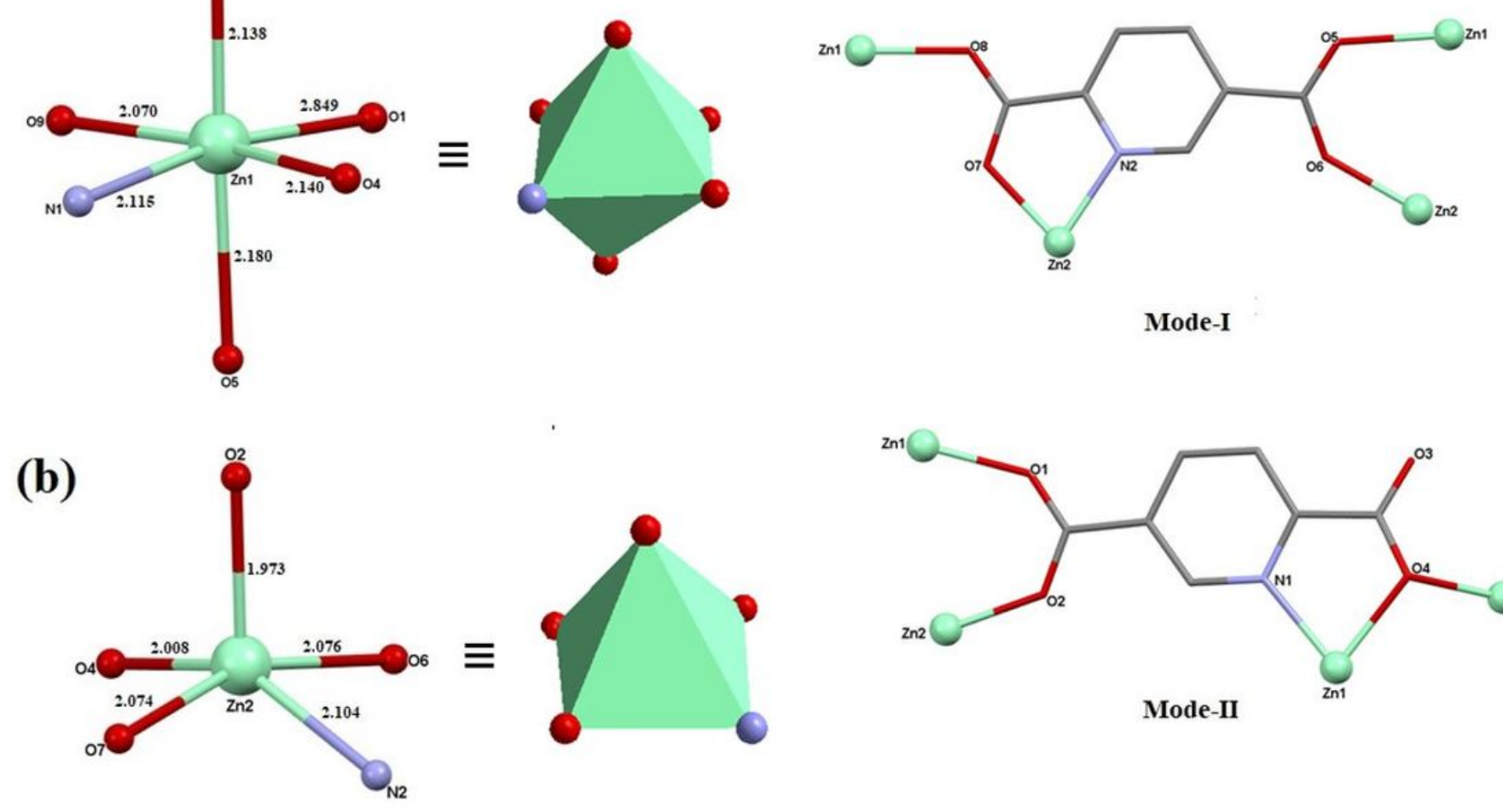

Mode-I

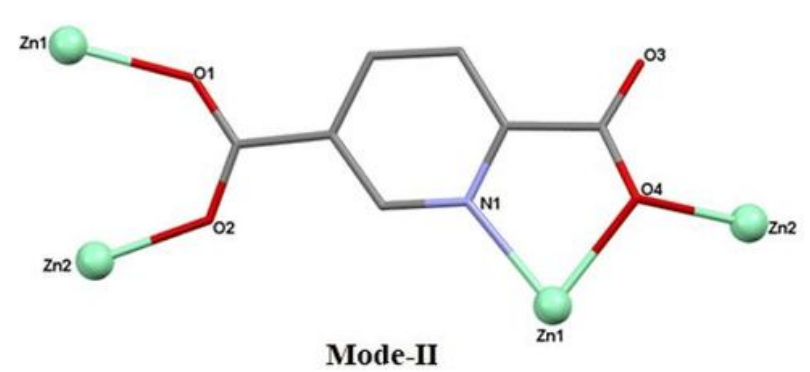

Figure 2

Six (a) and Five (b) coordinated geometry of Zn-MOF-1 with bond length (in $\AA$ ), (c) Distinct coordination modes of pydc2- in Zn-MOF-1.

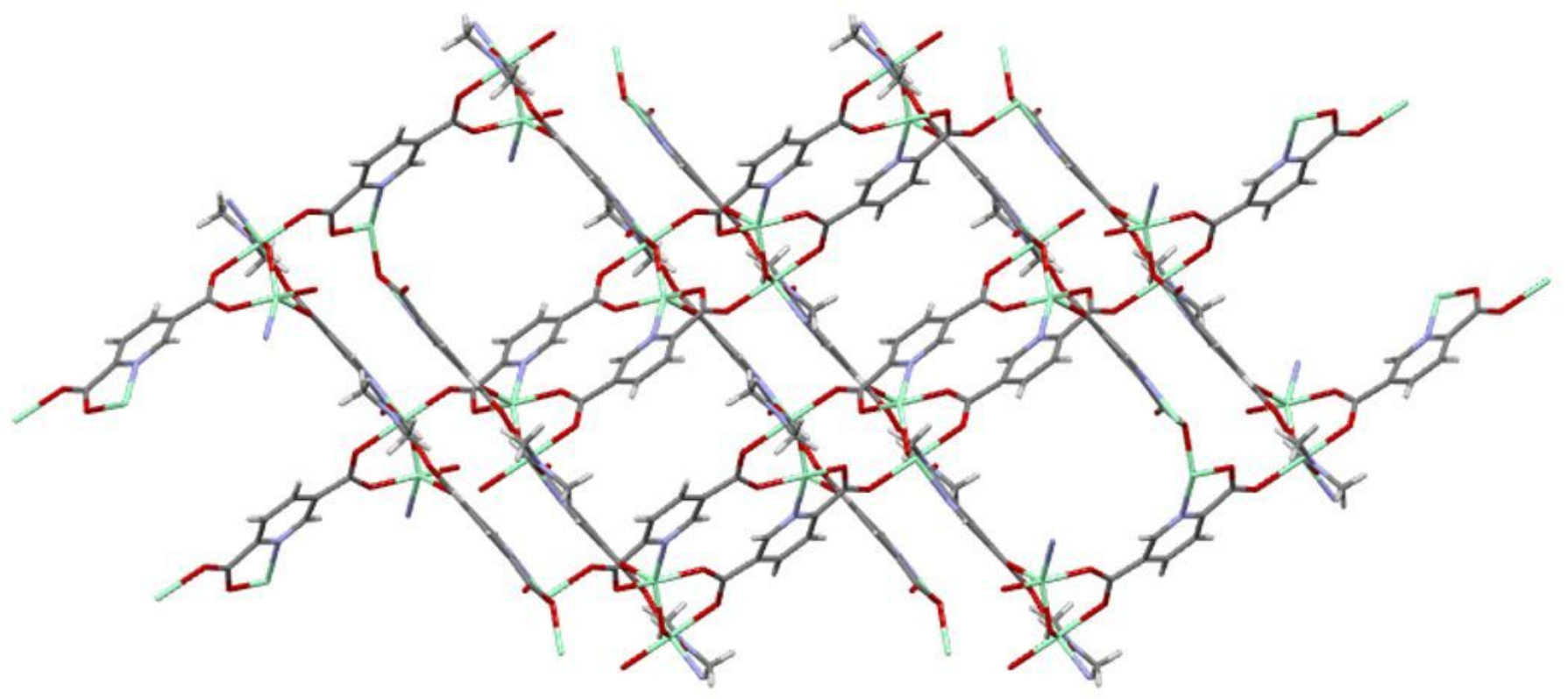

Figure 3

3D Network of Zn-MOF-1 viewed along [010]. 

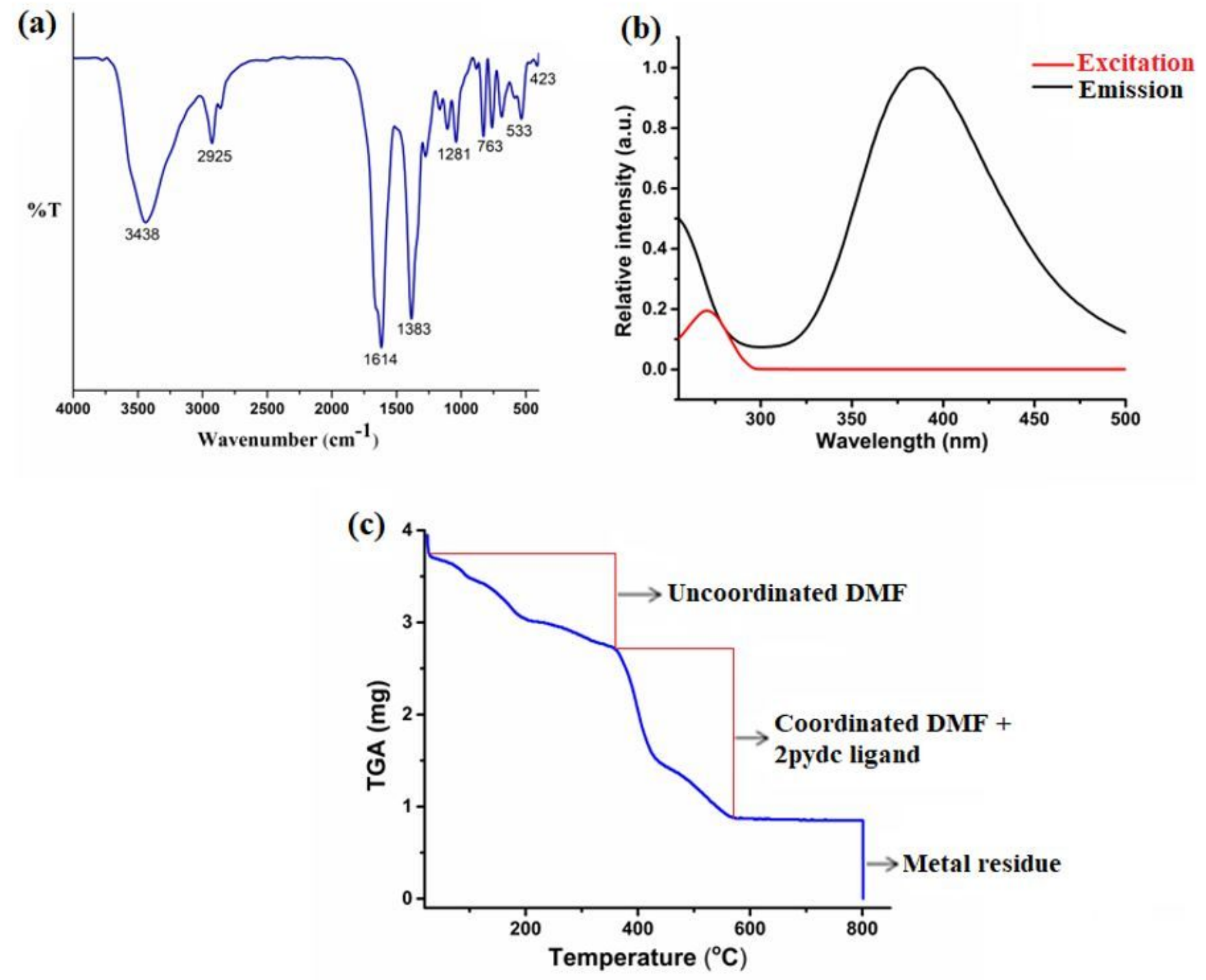

Figure 4

(a) FTIR spectra of Zn-MOF-1. (b) Absorption and Emission spectrum of Zn-MOF-1. (c) TG Analysis of ZnMOF-1. 


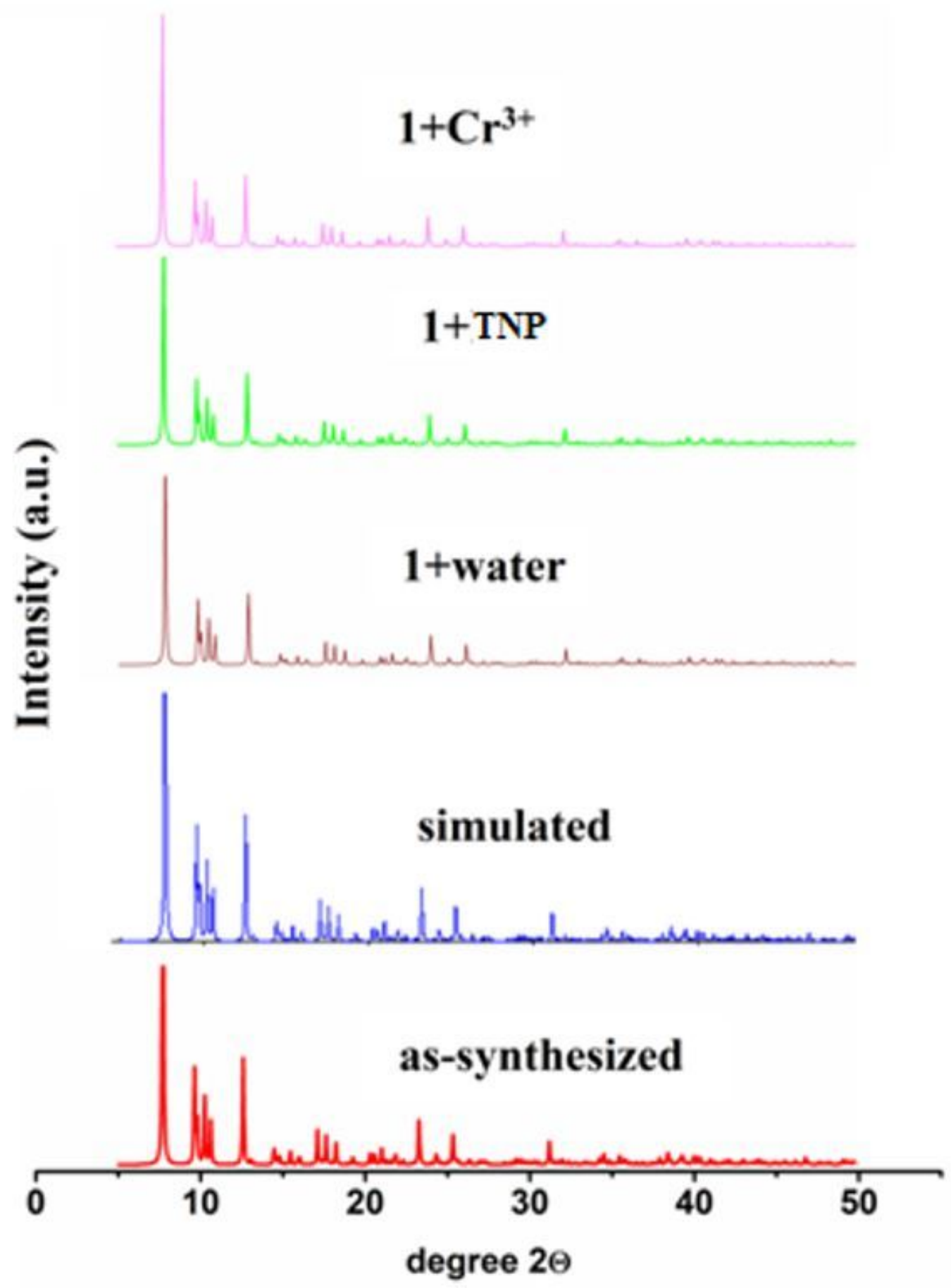

Figure 5

PXRD pattern of Zn-MOF-1 as synthesized, simulated, in water, in TNP and in Cr3+ ion. 


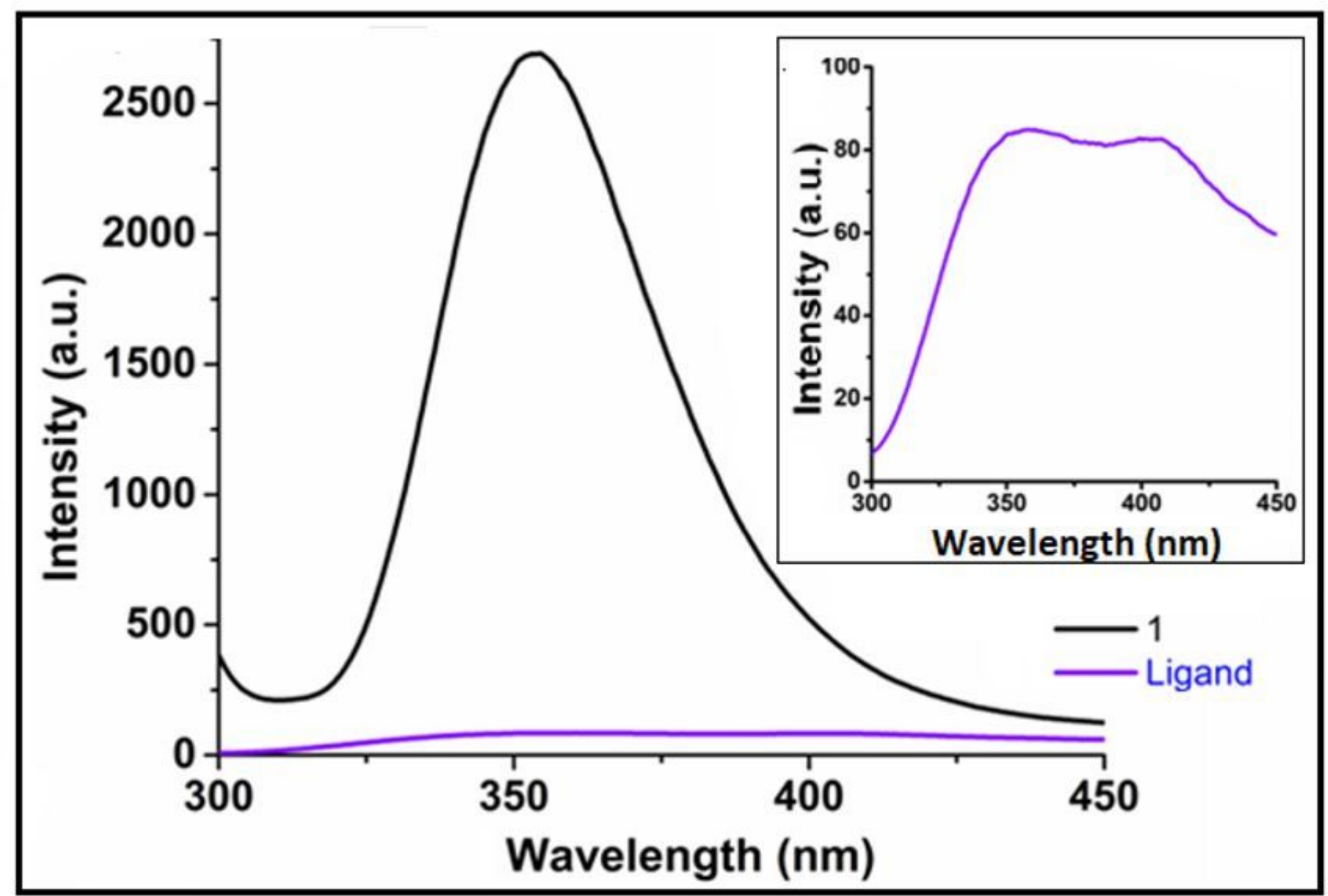

Figure 6

Emission spectrum of Zn-MOF-1 and pydc ligand (Inset: Emission spectrum of ligand upon excitation at $270 \mathrm{~nm})$. 

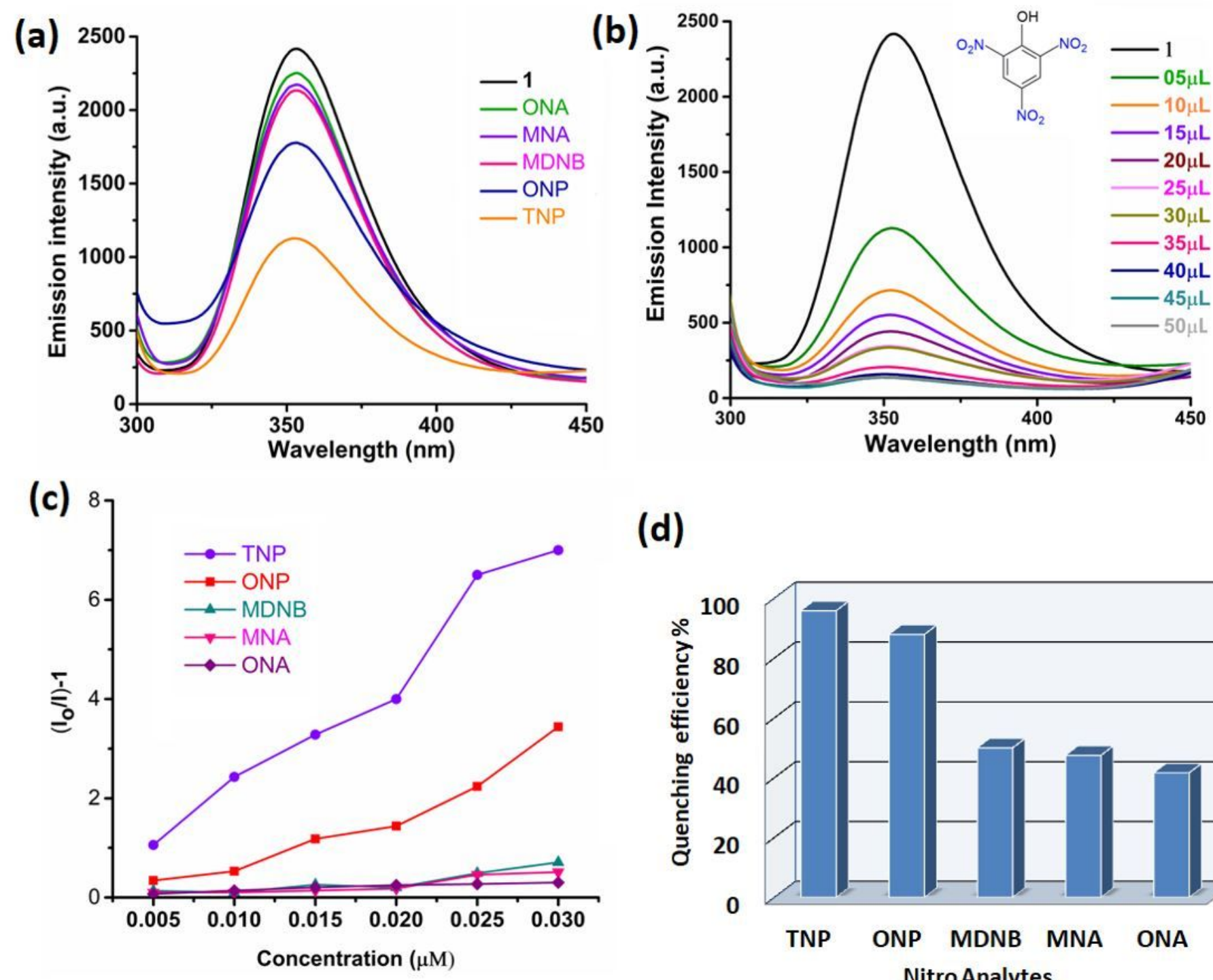

(d)

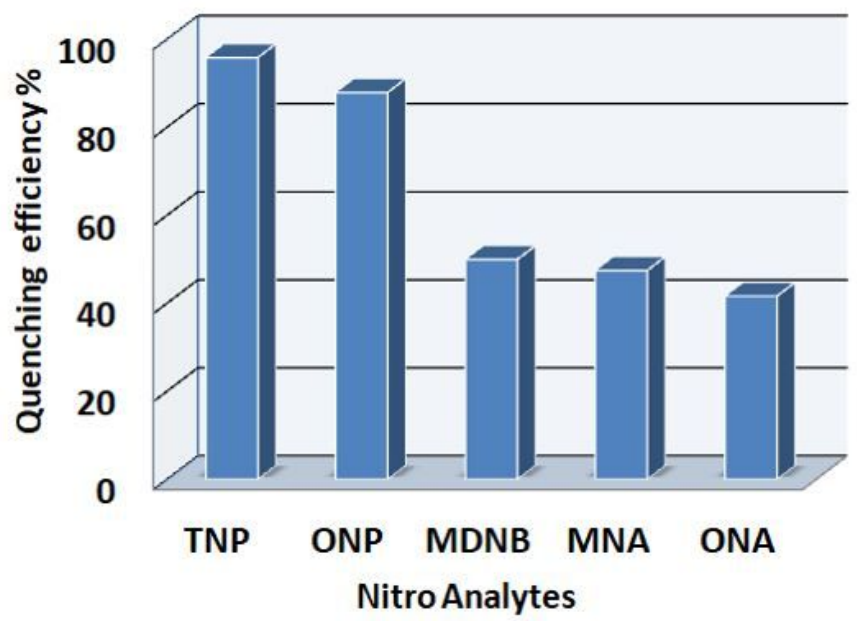

Figure 7

(a) The change in fluorescence intensity of Zn-MOF-1 $(\lambda e x=272 \mathrm{~nm})$ upon addition of $5 \mu$ l of different nitro analytes. (b) The change in fluorescence intensity of Zn-MOF-1 on incremental addition of TNP. (c) Stern-Volmer plot of various nitro analytes. (d) \% Quenching efficiency of various nitro analytes in presence of Zn-MOF-1. 


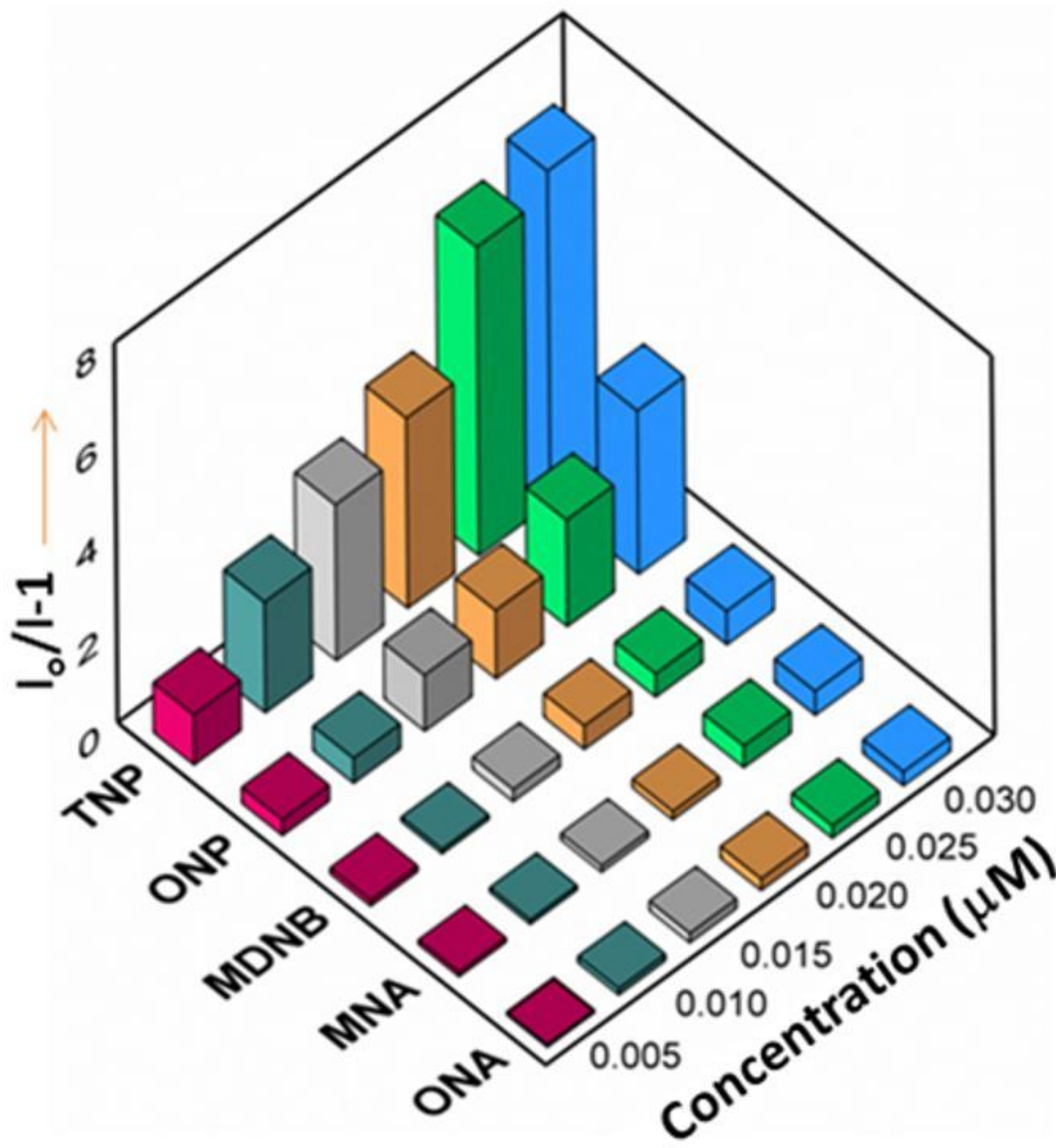

Figure 8

3D Stern-Volmer plot of various nitro analytes in water for Zn-MOF-1. 


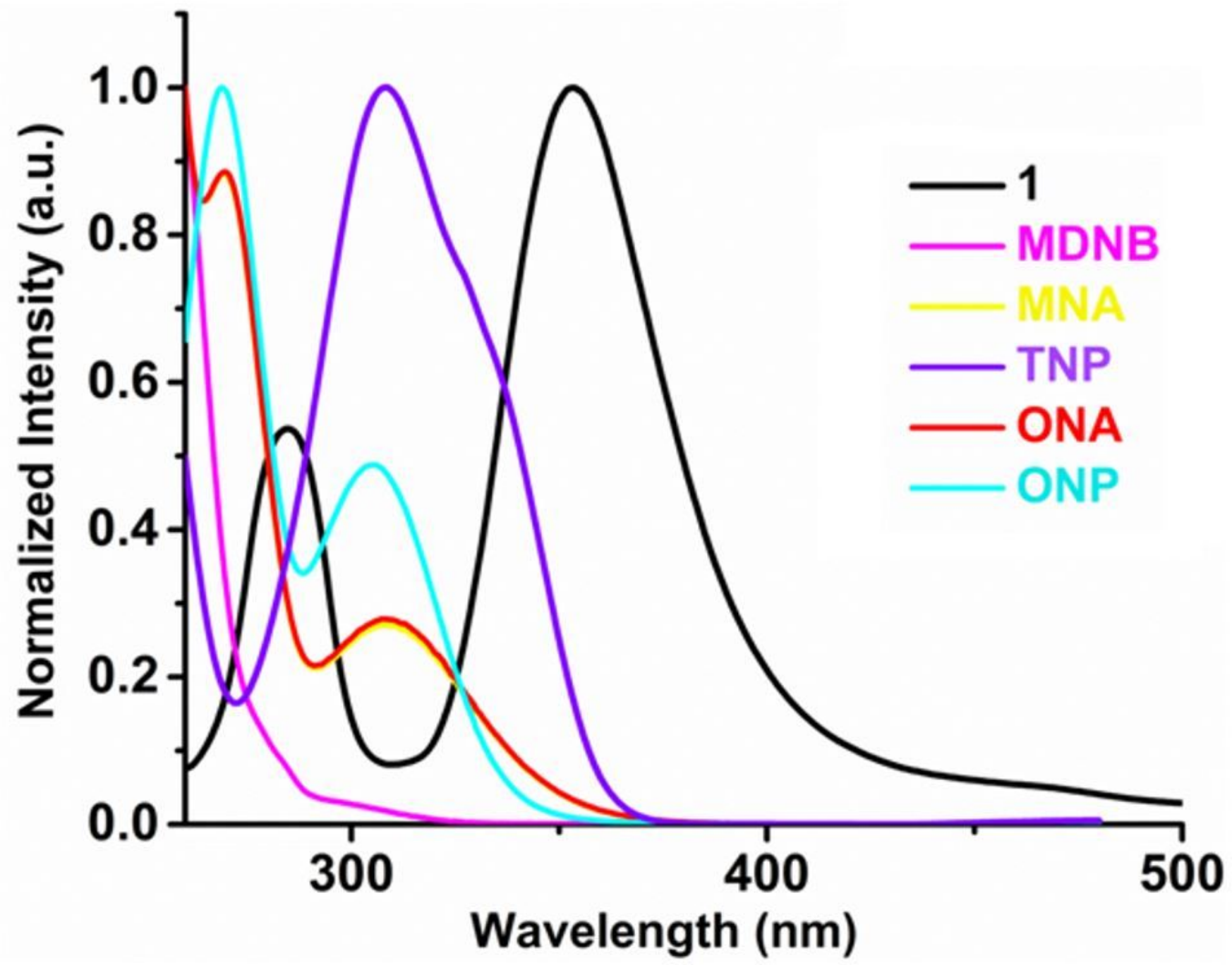

Figure 9

Spectral overlap between normalized emission spectra of Zn-MOF-1 $(\lambda e x=272 \mathrm{~nm})$ and normalized absorbance spectra of nitro analytes. 

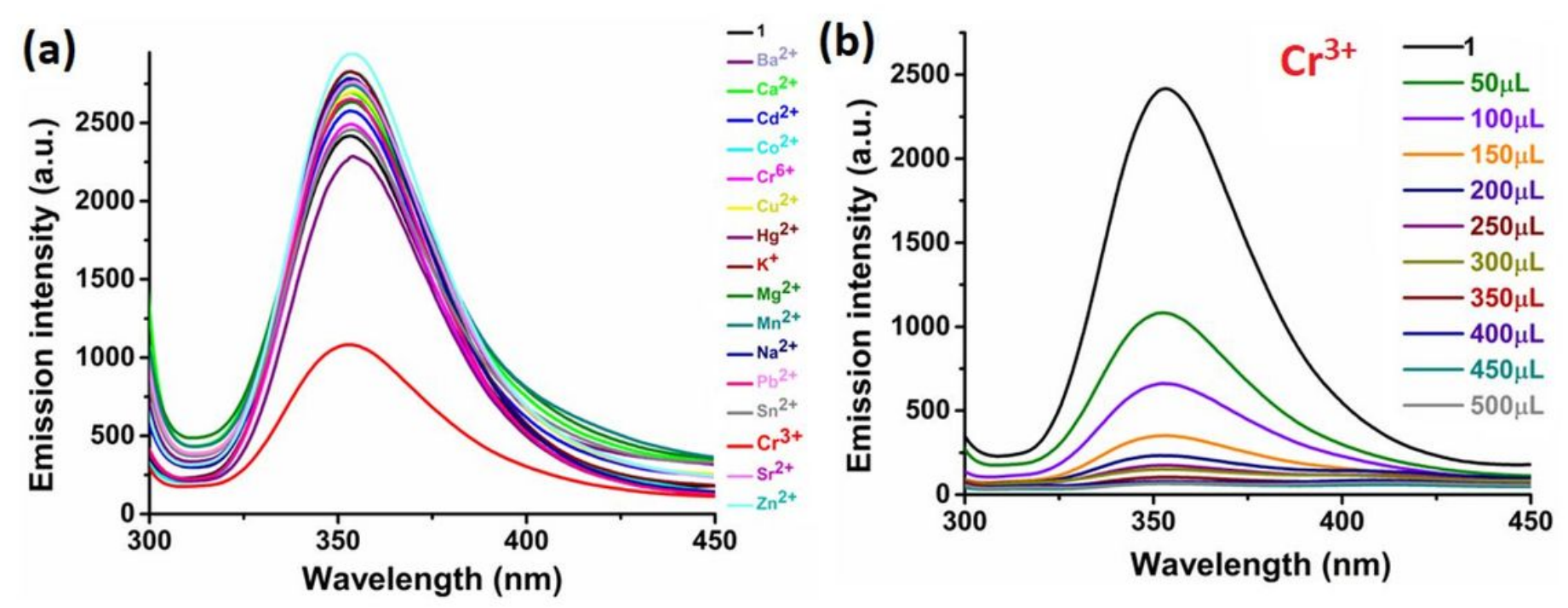

Figure 10

(a) The change in fluorescence intensity of Zn-MOF-1 $(\lambda e x=272 \mathrm{~nm})$ upon addition of different metal cations. (b) The change in fluorescence intensity of $\mathrm{Zn}-\mathrm{MOF}-1$ with incremental addition of $\mathrm{Cr} 3+$. 
(a)

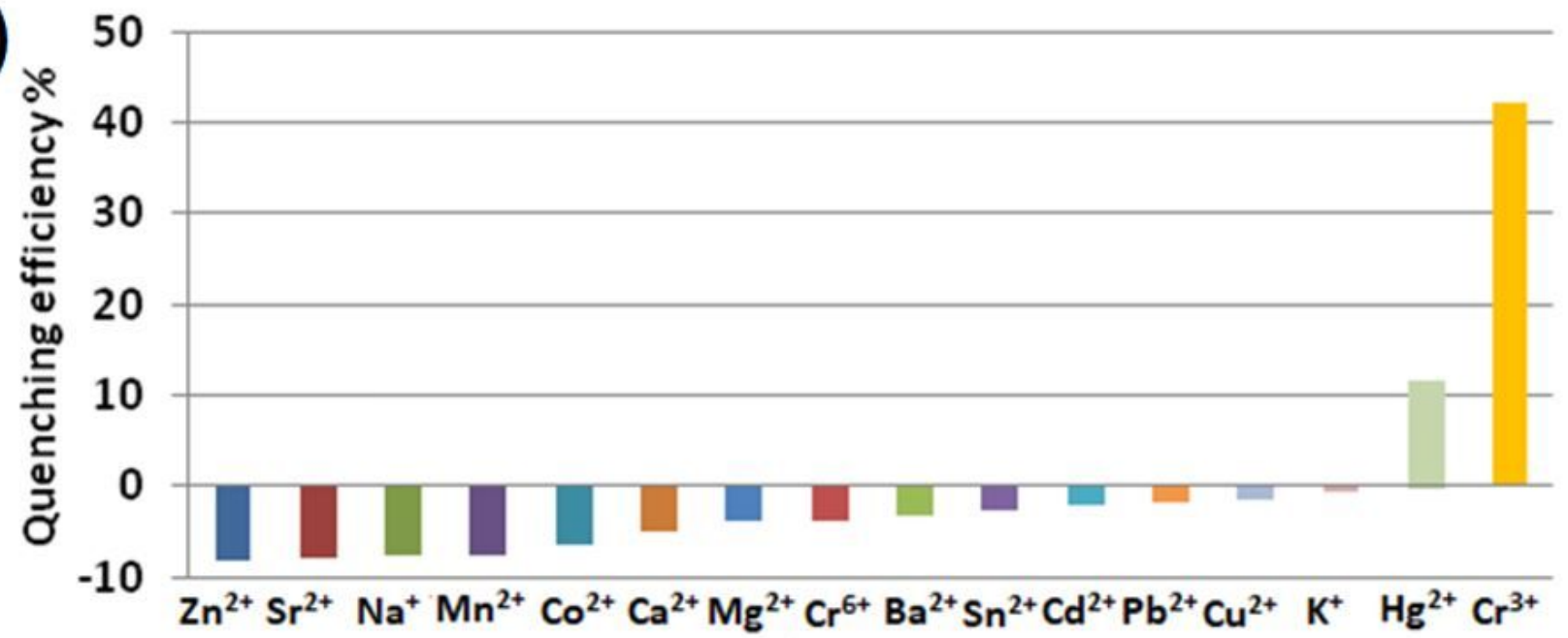

(b)

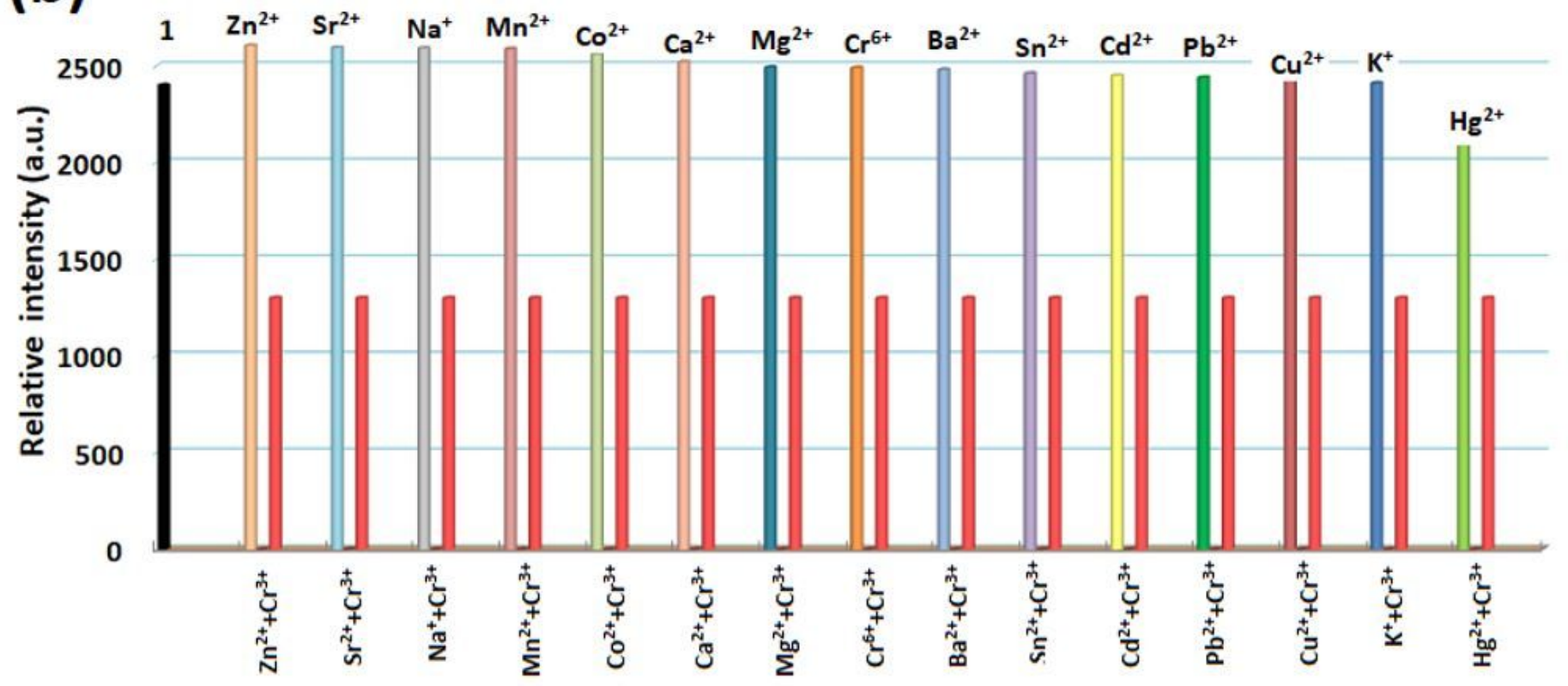

Figure 11

(a) The fluorescence quenching efficiencies of different analytes upon addition of 50 $\mu$ in Zn-MOF-1, (b) Change in fluorescence intensity of Zn-MOF-1 upon addition of different metal ion solution followed by $\mathrm{Cr} 3+$ solution respectively in water. 


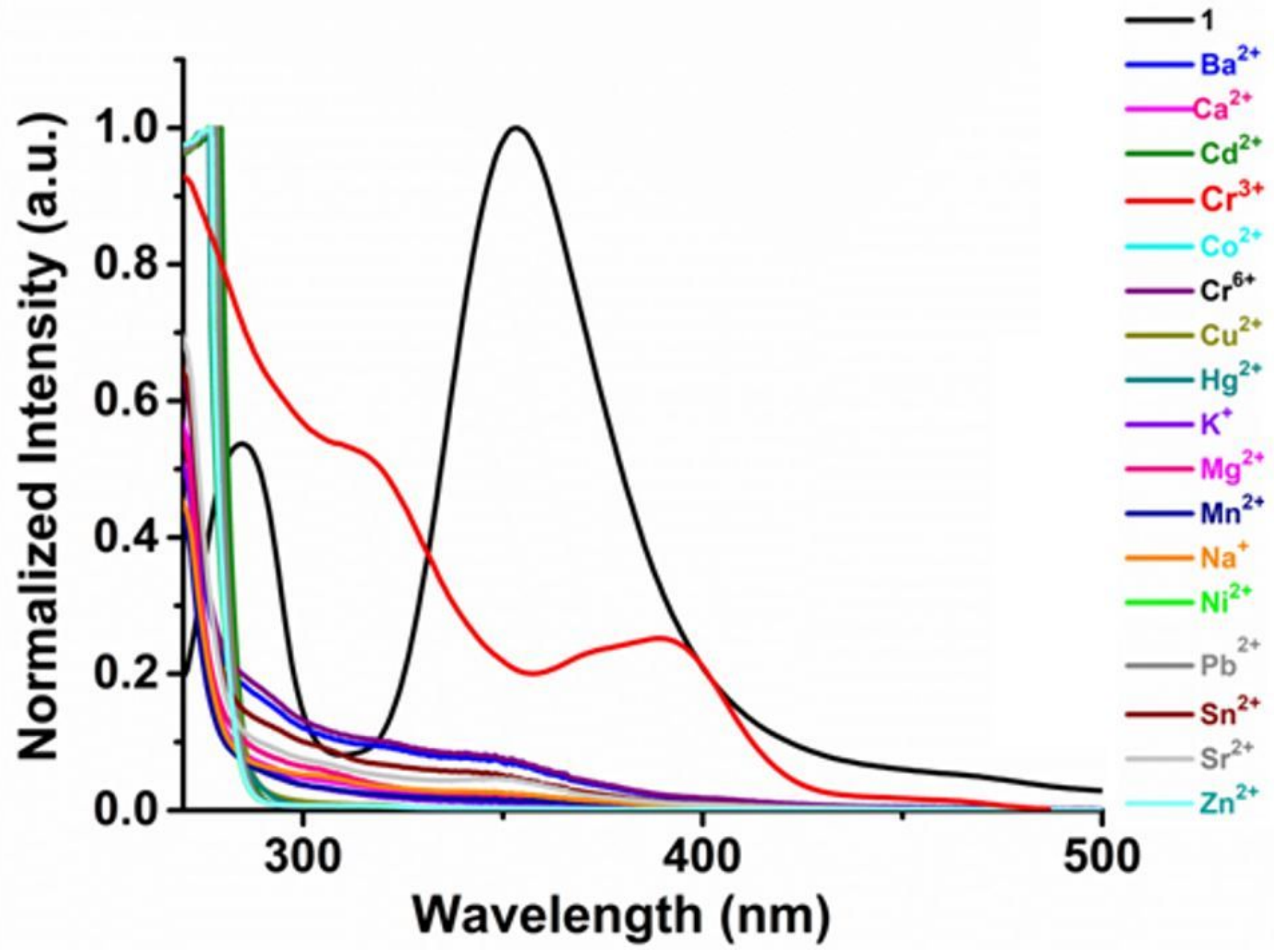

Figure 12

Spectral overlap between normalized emission spectra of Zn-MOF-1 $(\lambda e x=272 \mathrm{~nm})$ and normalized absorbance spectra of metal ions.

\section{Supplementary Files}

This is a list of supplementary files associated with this preprint. Click to download.

- scheme1.jpg

- scheme2.jpg

- ESIfile.docx

- GRAPHICALABSTRACTpictogram.docx

- GraphicalAbstractSynopsis.docx 